\title{
Tape cast isotropic, fine-grained tungsten for thermo-cyclic loading applications
}

\author{
Mathias Sommerer a, Muyuan Li b, Ewald Werner a, Hubertus von Dewitz c, Steffen Walter d, Stefan \\ Lampenscherf d, Thomas Arnold e

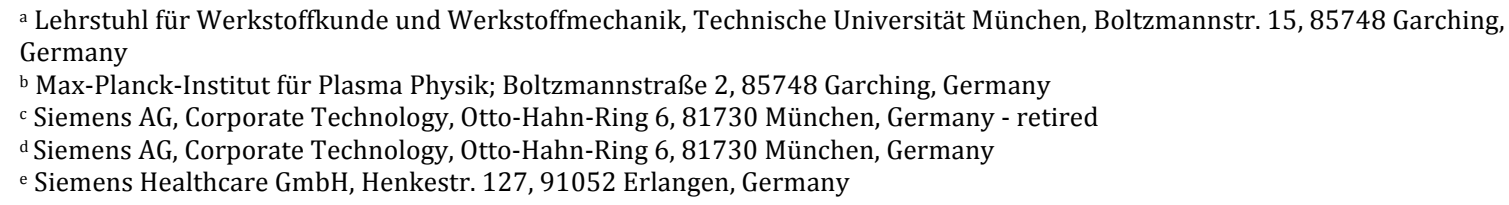

\begin{abstract}
This paper introduces tape casting as a new route for the production of isotropic and fine-grained tungsten components. Microstructural and thermal properties of tape cast tungsten samples are determined. Thermal shock behavior according to the thermo-cyclic loading of standing X-ray anodes is investigated and compared to the behavior of a rolled tungsten grade. The development of surface roughness during the thermal shock loading is discussed in relation to the development of the grain structure and crack pattern. The finegrained and stable microstructure of the tape cast material exhibits less roughening under such test conditions.
\end{abstract}

Keywords: tungsten, tape casting, thermal shock, HHF, fracture. 


\section{Introduction}

The extensive material research conducted in the field of fusion science has the potential to deliver new approaches and knowledge that could be beneficial for products other than those used in fusion devices. A broad technology scouting on material topics in fusion science indicated, that the thermo-cyclic loads of plasma facing materials (PFMs) in the blanket or divertor of a fusion reactor show similarities to the loadings of accelerator targets and X-ray anodes. In both applications tungsten or tungsten alloys are the preferred materials to withstand short-duration high heat-flux loadings. Especially critical events like edgelocalized-modes (ELMs) and vertical displacements (VDEs) limit the lifetime of PFMs [1-7]. The frequencies and power densities are roughly comparable to the load conditions applied to rotating and standing anodes in X-ray tubes [8, 9]. The understanding of the fracture mechanism of tungsten subjected to thermo-cyclic loading [7, 10-23] in fusion applications and the development of new, optimized tungsten grades therefore can also lead to new or improved materials for X-ray anodes.

Studies on the fracture mechanism of rolled tungsten grades revealed that an oriented microstructure exhibits higher fracture toughness in case of transgranular crack propagation perpendicular to the preferred direction of elongated grains [19], whereas lower fracture toughness and intergranular crack propagation are observed in case of crack propagation parallel to the preferred grain direction. Thereby intergranular crack propagation leads to an increasing critical stress intensity factor with continuously increasing crack length. This is described as a pseudo-ductile R-curve behavior in [11]. Isotropic tungsten grades are also dominated by an intergranular fracture behavior in cases of thermo-cyclic loading and they show improved ductility and a reduction of the ductile-brittle-transition-temperature (DBTT) $[7,10-23]$.

Especially fine-grained materials are preferred solutions to withstand thermo-cyclic loadings as they also possess both higher yield and fracture strength and an improved ductility due to a lower concentration of impurities at the grain boundaries [24]. For high temperature applications e.g. in the divertor and the blanket of a fusion reactor, a further option to improve the material is to use thermally stable dispersoids to prevent grain growth in these finegrained microstructures, as shown e.g. by Kurishita et al. [15, 25].

The production of most of these fine grained, isotropic and thermally stable tungsten grades is currently available only in lab scale amounts and therefore result in small sample 
sizes. One process to produce special tungsten grades in larger volume is powder injection molding (PIM), which is commercially available at the Energy Research Centre of the Netherlands (ECN) [26]. The process is especially suitable for the production of larger amounts of smaller components with a complex geometry, such as e.g. the divertor tiles [27].

Tape casting has been proposed by Siemens AG, Germany, as an alternative route for the fabrication of isotropic tungsten. The process is especially suitable for the production of large, flat components like X-ray anodes and targets. As tape casting shows some similarities (shaping of a tungsten slurry/ feedstock that is heat treated afterwards) to the PIM-process, the realization of a fine-grained and isotropic microstructure should also be achievable by this process.

Our contribution describes the technical parameters of processing and the achieved material properties of tape cast tungsten (W-TC). The material is tested according to the load conditions of standing X-ray tube anodes at a heat flux test facility at Siemens Healthcare, Germany. Finally the thermo-cyclic behavior of W-TC is compared to a commercially available (W-ST, Standard), rolled tungsten grade $(99.9 \% \mathrm{~W})$ produced by Plansee AG, Austria. The reference material is tested analogously at different power densities and number of repetitions of thermal loads.

\section{Tape casting process}

The flow of the tape casting process and the sketch of a tape casting equipment can be seen in Fig. 1. Tungsten powders are mixed with organic additives (Tab. 1) to produce a slurry, which is poured onto a carrier tape. The thickness of the green tape is adjusted by the viscosity of the slurry, the height of the doctor blade gap and the velocity of the carrier tape (Fig. 1). After drying the green tape in air for 3 hours, where already some of the solvent evaporates, the tape can be formed and cut to size. The maximum available height of the doctor blade gap in this work was $200 \mu \mathrm{m}$. In order to produce tungsten samples with a final thickness between $2 \mathrm{~mm}$ and $2.5 \mathrm{~mm}$ several layers of the original green tape were laminated to thicker sheets by isostatic pressing at $80^{\circ} \mathrm{C}$. Finally, the laminate was cut to size (considering roughly $20 \%$ of volumetric shrinkage) and then heat treated. 
a) Principle of a tape caster

b) Process flow
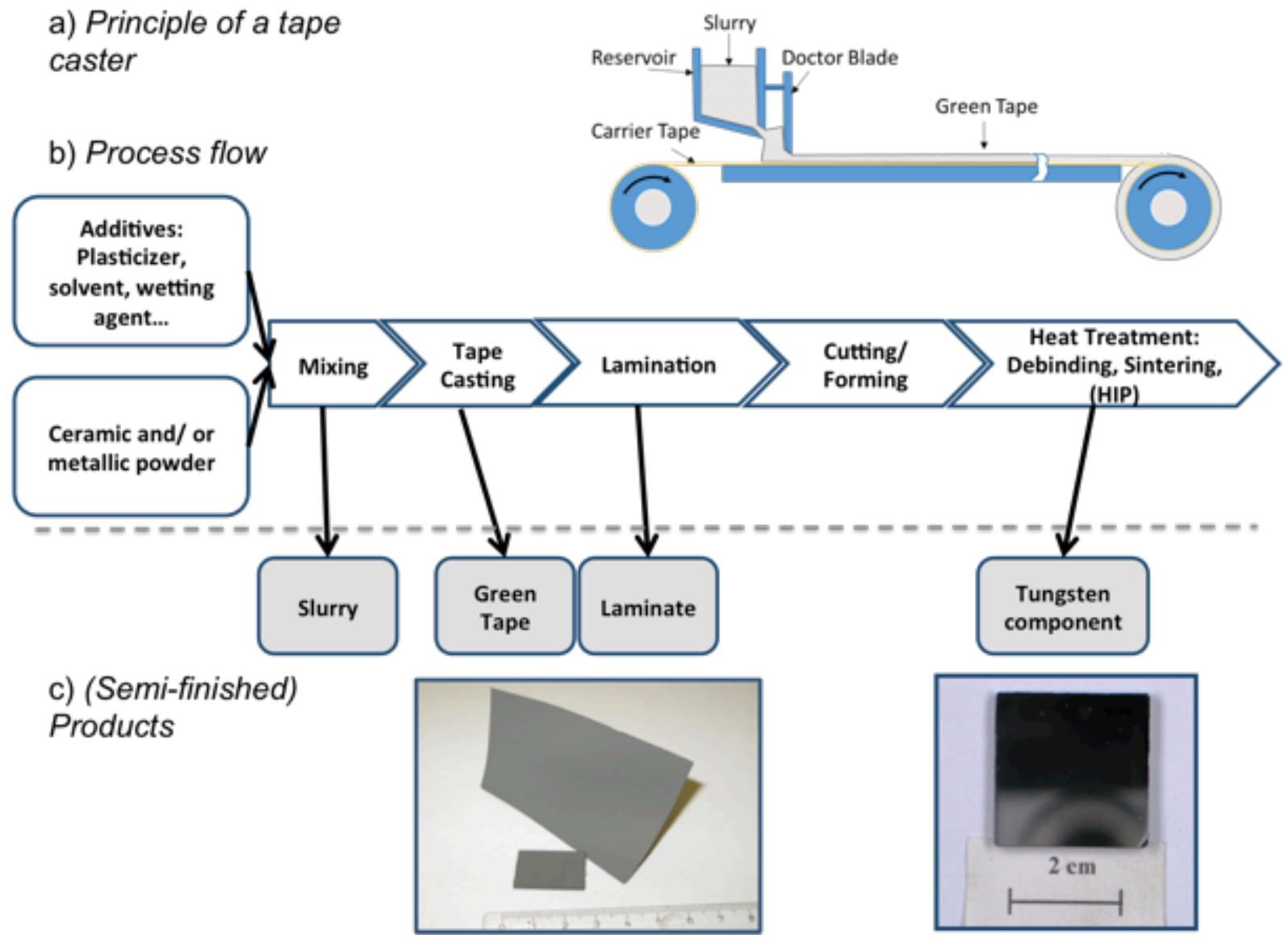

Fig. 1: a) Sketch of the tape casting equipment, b) process flow of tape casting and c) green tape and sample of tape cast tungsten.

According to the development of tungsten via PIM by Zeep [28] a powder composition of 50 weight- $\%$ tungsten powder with a median particle diameter (D50) of $0.46 \mu \mathrm{m}$ and 50 weight-\% with a D50 of $1.87 \mu \mathrm{m}$ were mixed with organic additives as listed in Tab. 1. A final organic content of 10 weight- $\%$ was realized by iterative mixing and casting experiments aiming at less organic content in the slurry and the avoidance of particle agglomeration.

Tab. 1: Ingredients of the tungsten slurry

\begin{tabular}{l|l} 
Tungsten powder & $\begin{array}{l}\text { 50 weight-\% HC 70 S (D50: 0.46 } \mu \mathrm{m}) \\
50 \text { weight-\% HC 170 S (D50: } 1.87 \mu \mathrm{m})\end{array}$ \\
\hline Solvent & Ethanol; Toluol \\
\hline Additive & Buty-Penthylphtalat \\
\hline Dispergator & Hypermer KD1 \\
\hline Organic binder & Pioloform BR 18 (PVB)
\end{tabular}

The final heat treatment was conducted in three steps. Debinding of the organic content and presintering were carried out in $\mathrm{H}_{2}$-atmosphere at up to $990{ }^{\circ} \mathrm{C}$ in an oxide lined furnace at 
heating rates of $1 \mathrm{~K} / \mathrm{min}$ to $3 \mathrm{~K} / \mathrm{min}$. The parts then were sintered at $1680{ }^{\circ} \mathrm{C}$ for $2 \mathrm{~h}$ in $\mathrm{H}_{2}$ atmosphere in a molybdenum lined furnace. Final densification by hot isostatic pressing (HIP) was performed at $1500{ }^{\circ} \mathrm{C}$ for 3 hours at a maximum available pressure of $172 \mathrm{MPa}$ (graphite lined furnace). A maximum pressure of $250 \mathrm{MPa}$, as recommended by Zeep [28], could not be reached with the available HIP-equipment.

\section{Experimental details}

\subsection{Thermal shock test}

A test facility for the experimental simulation of thermal shocks according to standing anode load conditions was used at Siemens Healthcare (Fig. 2).

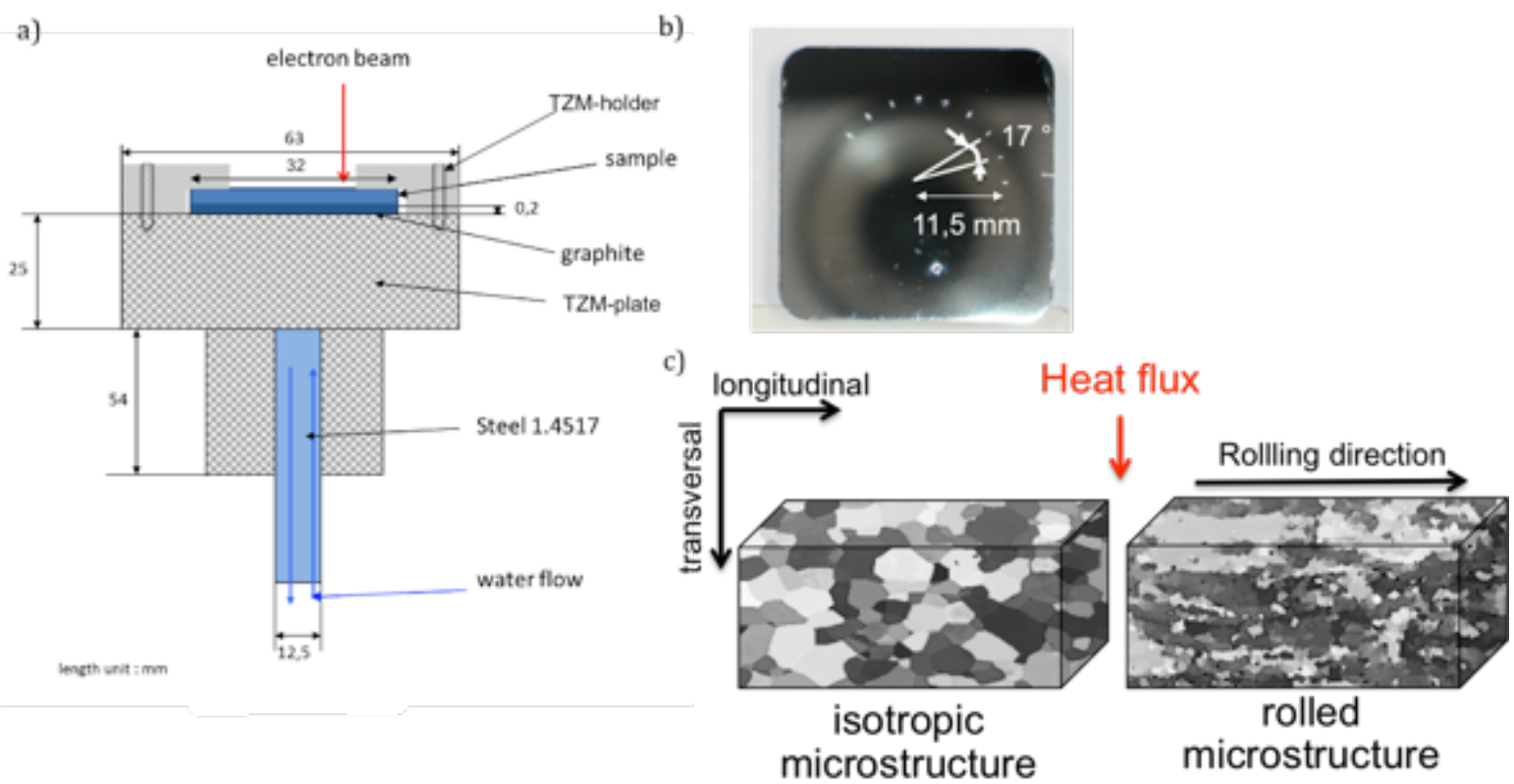

Fig. 2: Setup of the thermal shock test facility at Siemens Healthcare: a) schematic drawing of the cross-section of the components in the heat-flux of the test facility; b) test positions on a W-ST sample; c) microstructural orientations and notations.

Samples of W-TC and W-ST (polished surface quality) with a size of $27.5 \mathrm{~mm} \times 27.5 \mathrm{~mm} \times$ 2.0 to $2.5 \mathrm{~mm}$ were fixed in a holder made of titanium-zirconium-molybdenum (TZM), on a TZM-plate. The plate was cooled at its backside with water (water flow: $2.51 / \mathrm{min}$ ). A flexible graphite sheet improved contact and hence heat transfer between the sample and the TZMplate.

Thermal shock loading was applied to the tungsten samples by an electron beam for $0.5 \mathrm{~s}$ in transversal direction of the sample (perpendicular to the rolling direction of W-ST, Fig. 2c) at room temperature (RT) The focal spot of the electron beam was of elliptical geometry (target value of length $\mathrm{x}$ width: $1024 \mu \mathrm{m} \times 204 \mu \mathrm{m}$ ) and the electron beam was 
adjusted to have a nearly Gaussian energy distribution. Further beam pulses were applied after a cooling period of $4.5 \mathrm{~s}$, which is according to numerical calculations enough to cool down to RT again. By varying the beam current at a constant voltage of $65 \mathrm{kV}$ different power densities were adjusted and combined with a certain number of electron-beam-pulses. In this way a matrix of load conditions (Tab. 2) was applied to the individual samples, as standing anodes in reality are also subjected to a broad rang of loadings. The worst conditions with regard to the crack formation are assumed to occur at loadings with power densities leading to peak temperatures (thermal shock experiment starting at RT) close to the melting point of the materials. With an increasing number of repetitions the failure development can be observed. The loaded positions on the sample are positioned on a circle at an angular distance of $17^{\circ}$ and at a radius of $11.5 \mathrm{~mm}$ (Fig. 2b). Due to the higher thermal diffusivity of W-ST (Fig. 5) lower peak temperatures were achieved at the surface of the W-ST sample at the same power density (details are reported in section 4.2). For that reason W-ST was also tested at a higher maximum, absorbed power density of $858 \mathrm{MW} / \mathrm{m}^{2}$. Due to the reflection and the scattering of electrons only a portion of the applied power density is absorbed by the material. The absorbed power densities are calculated from the applied power densities using an absorption factor of 0.55 , which is also used in [14] and deduced from Monte-Carlo simulations. Measured absorption coefficients of tungsten between 0.48 and 0.66 are discussed in literature $[7,21,29,30]$.

Tab. 2: Test matrix of the thermal shock test for W-TC (x) and W-ST (o).

\begin{tabular}{|c|c|c|c|c|c|}
\hline \multirow{2}{*}{$\begin{array}{c}\text { Absorbed power } \\
\text { density } \\
{\left[\mathrm{MW} / \mathrm{m}^{2}\right]}\end{array}$} & \multicolumn{5}{|c|}{ Number of repetitions } \\
\hline & 1 & 10 & 25 & 50 & 100 \\
\hline 286 & $\mathrm{x}$ & $\mathrm{X}$ & $\mathrm{x}$ & $\mathrm{X}$ & $\mathrm{X}$ \\
\hline 429 & $\mathrm{X}, \mathrm{O}$ & $\mathrm{X}, \mathrm{O}$ & $\mathrm{X}, \mathrm{O}$ & $\mathrm{X}, \mathrm{O}$ & $\mathrm{X}, \mathrm{O}$ \\
\hline 572 & $\mathrm{x}, \mathrm{O}$ & $\mathrm{x}, \mathrm{O}$ & $\mathrm{x}, \mathrm{O}$ & $\mathrm{x}, \mathrm{O}$ & $\mathrm{x}, \mathrm{O}$ \\
\hline 715 & $\mathrm{x}, \mathrm{O}$ & $\mathrm{o}$ & o & $\mathrm{o}$ & $\mathrm{x}, \mathrm{O}$ \\
\hline 858 & o & & & & 0 \\
\hline
\end{tabular}

Post-mortem characterizations of the tested samples were performed by microscopic means and laser profilometry.

\subsection{Microscopy}

For the analysis of microstructural changes and the fracture pattern in the focal spot scanning electron microscopy was conducted in a field emission microscope JEOL JSM$7600 \mathrm{~F}$ (FEM) using both secondary- and back-scattered-electron-mode (SE and BSE). 
Additional characterization by electron backscatter diffraction (EBSD) was carried out in a microscope JEOL 6490 equipped with a tungsten cathode. The grain size was evaluated from the EBSD measurements. Thereby a grain boundary was defined if the misorientation angle between a measuring point and its five nearest neighbors was larger than $5^{\circ}$ [31]. According to Mackenzie [32] the misorientation angle is defined as the smallest rotation angle around a common axis, which rotates one crystal into the neighboring one [33].

The surface of the samples was prepared for microstructural investigations according to the recipe of Manhard et al. [34] before the thermal shock test. The polishing force recommended in this study was increased to $45 \mathrm{~N}$ due to the large sample size.

\subsection{Laser profilometry}

Thermal shock loadings may cause deformation and cracking of the samples surface. The 3D-laserscan-microscope Keyence VK-9700 was used to measure the average surface roughness $\mathrm{R}_{\mathrm{a}}$ and maximum waviness $\mathrm{W}_{\mathrm{z}}$ in the focal spot. The measured data were evaluated with the software VK-Analyse-Modul, Version 3.3.0.0 [35]. The different wavelength of roughness and waviness are separated from the raw profile using a cut-off wavelength $\lambda_{\mathrm{C}}$ of $0.08 \mathrm{~mm}$. In that way the effect of surface elevation can be distinguished from short-range effects like e.g. cracking. Fig. 3 describes the procedure exemplarily:
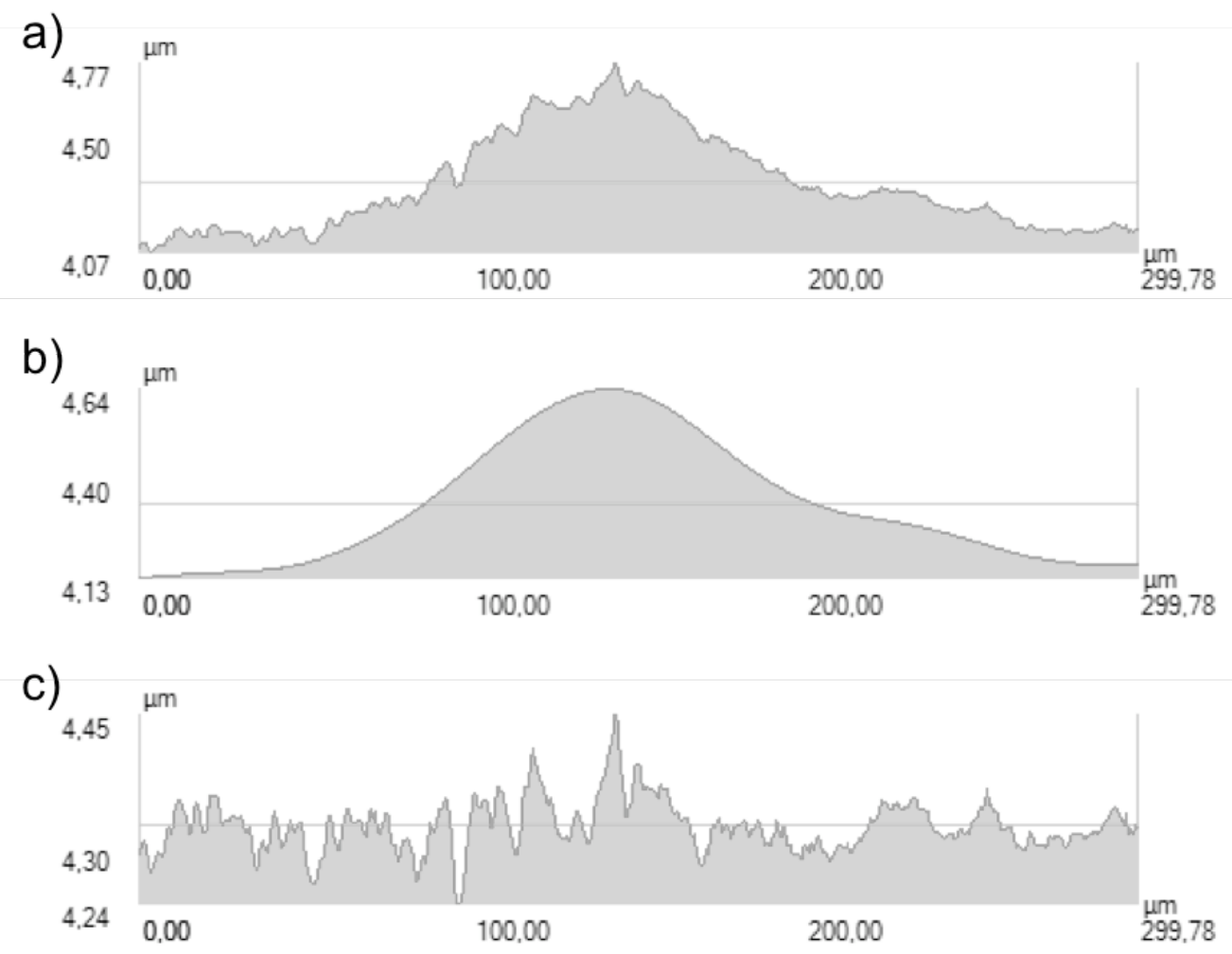

Fig. 3: Processing of the surface profile through the use of a filter with a cut-off wavelength $\lambda_{C}$ of $0,08 \mathrm{~mm}$ : a) raw profile, b) profile of waviness, c) profile of roughness 
$\mathrm{R}_{\mathrm{a}}$ was calculated from 11 line profiles roughly perpendicular to the major axis of the focal spot (analyzed segment length $\approx 100 \mu \mathrm{m}$ ), whereas $\mathrm{W}_{\mathrm{z}}$ was evaluated from an area measurement $(500 \mu \mathrm{m} \times 700 \mu \mathrm{m})$, which covered the whole focal spot.

\subsection{Thermal diffusivity, impurities and density}

The thermal diffusivity is one of the key parameters for thermal shock loaded materials as it defines the temperature depended thermal conductivity $\lambda(T)$ according to

$\lambda(T)=\alpha(T) \cdot \rho(T) \cdot c(T)$,

where $\alpha(T)$ is the thermal diffusivity, $\rho(T)$ ist the density and $c(T)$ is the specific heat. The peak temperatures of the surface [14] and accordingly the generated thermal strains are related to these parameters. Using the laser flash method [36] the thermal diffusivity was determined in transversal direction of the samples (Fig. 2). The measurement was performed in vacuum from room temperature (RT) to $1300{ }^{\circ} \mathrm{C}$ in a Netzsch LFA 427 . In order to reduce laser reflection the samples were roughened by sand blasting before measurement. The density at room temperature $\rho_{0}$ was measured according to Archimedes` principle with samples submersed in ethanol. The density $\rho$ at a temperature $T$ was then calculated via the temperature dependent thermal expansion coefficient $\alpha(T)$ of the materials according to:

$\rho(T)=\frac{\rho_{0}}{1+3 \cdot \alpha(T) \cdot T}$

The temperature dependent thermal expansion coefficient and specific heat $c(T)$ is taken from measurements and a database [37] at Siemens Healthcare.

Since too high heating rates or too low gas flow during the debinding process could promote cracking of polymer chains and lead to a residual carbon content in the sample, the carbon content was measured according to DIN EN ISO 9556:2001 in a carbon analyzer CS 800 from ELTRA at the laboratory of H.C. Starck Ceramics GmbH.

\section{Results}

\subsection{Microstructure and properties of as-produced material}

A final density between $18.4 \mathrm{~g} / \mathrm{cm}^{3}$ and $18.5 \mathrm{~g} / \mathrm{cm}^{3}$ was achieved in the W-TC samples. The lower density of W-TC compared to the theoretical density of tungsten $\left(19.3 \mathrm{~g} / \mathrm{cm}^{3}\right)$ is mainly affiliated to porosity (Fig. 4). Also a higher carbon content of up to $1600 \mathrm{ppm}$ is measured in that batch of samples. 

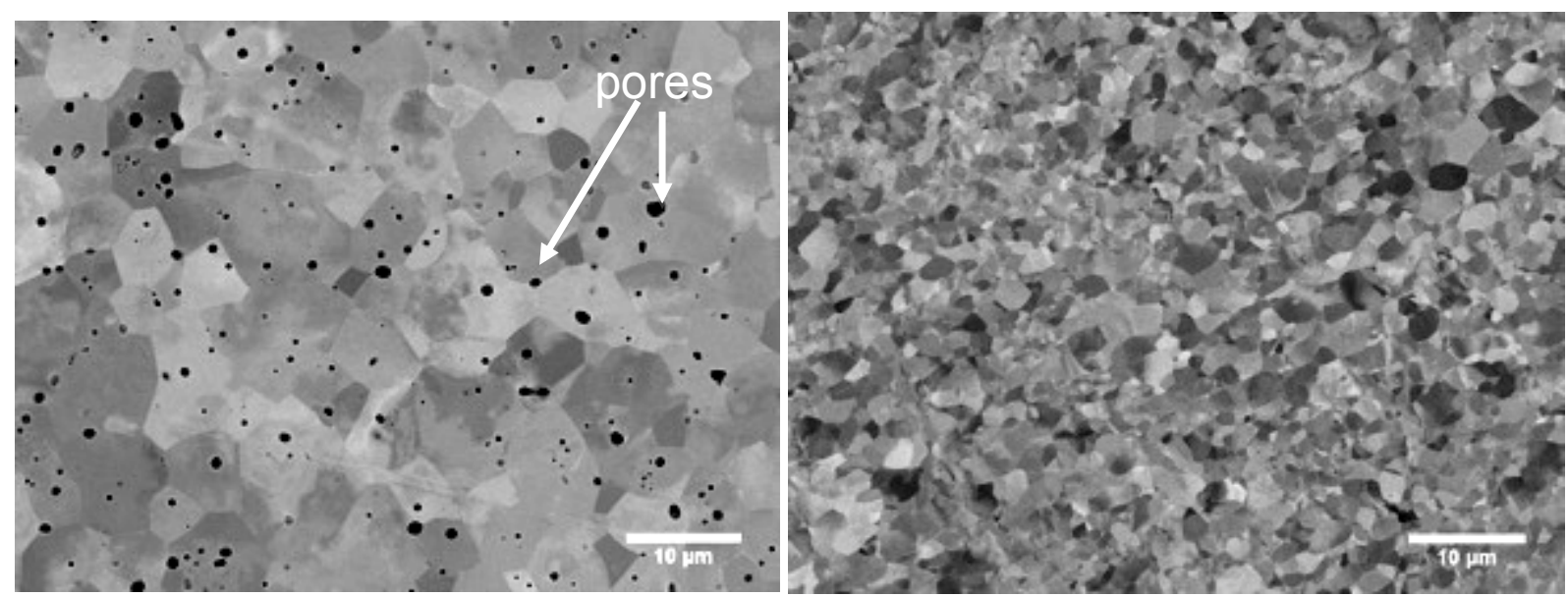

Fig. 4: Microstructure of as-produced W-TC (left) and W-ST (right) in BSE images.

The reference material W-ST shows no porosity and a low carbon content $(<10 \mathrm{ppm})$. The density of the W-ST samples is $19.2 \mathrm{~g} / \mathrm{cm}^{2}$. The thermal diffusivity from RT to $1300{ }^{\circ} \mathrm{C}$ is nearly $20 \%$ higher for W-ST than in W-TC (Fig. 5), indicating a higher amount of defects in W-TC (e.g. pores, impurities), which scatter electrons.

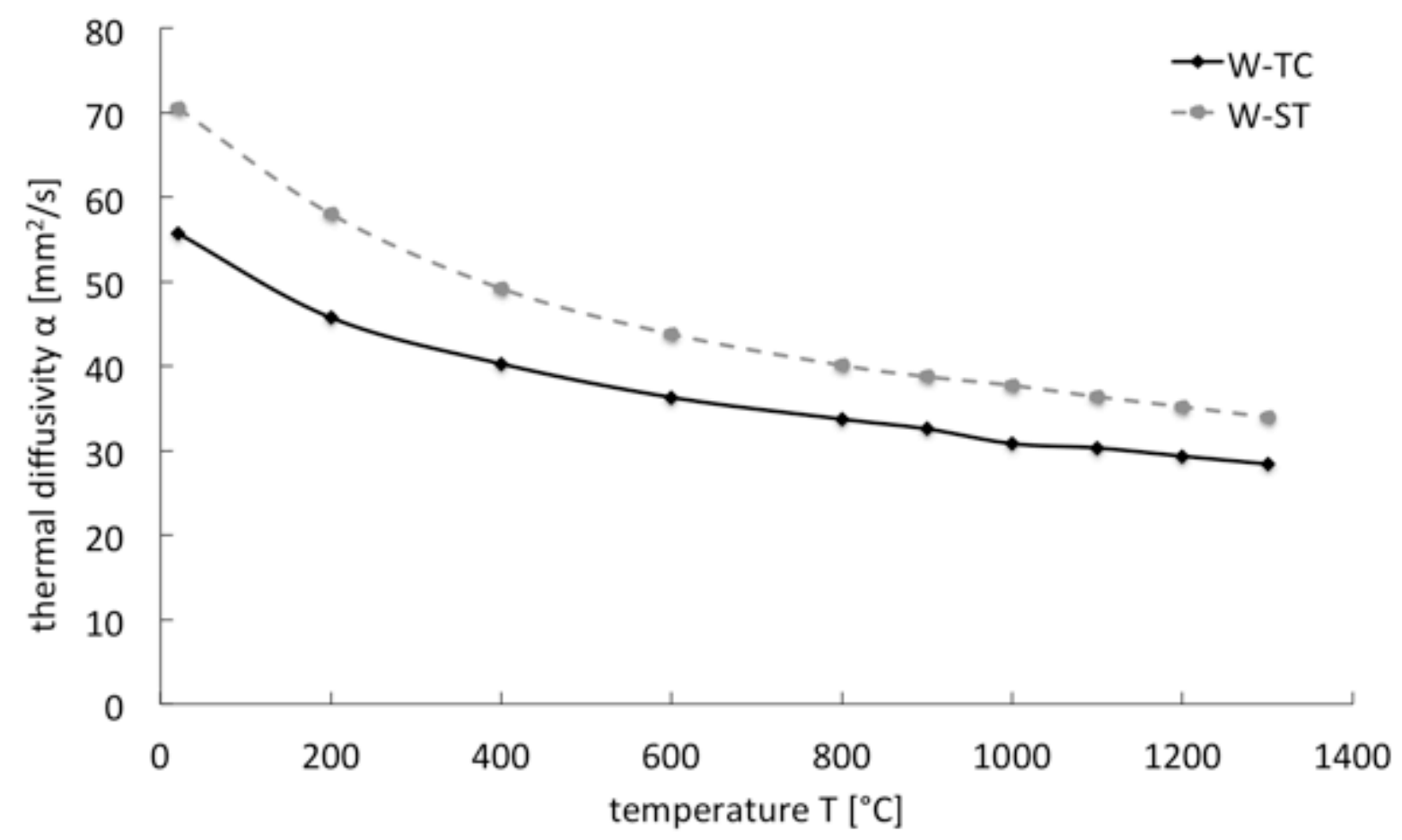

Fig. 5: Thermal diffusivity of W-TC and W-ST as a function of temperature.

W-TC exhibits an isotropic microstructure with a distribution of the grain boundary misorientation angle (Fig. 6) apparently being close to Mackenzie`s distribution [32]. Prantl et al. [38] recommended the $\chi^{2}$-test to proof the congruency of the measured distribution and Mackenzie's distribution. The deviation $\chi_{0}^{2}$ from the theoretical distribution should not 
exceed a critical value for the distributions to match. For a $\chi^{2}$-test between $0^{\circ}$ and $60^{\circ}(12$ intervals, interval width $5^{\circ}, 11$ degrees of freedom) and a significance level of $5 \%$ the critical value is 19.68 [39]. For W-TC $\chi_{0}{ }^{2}$ was calculated to be 202, whereas the deviation $\chi_{0}{ }^{2}$ is 1100224 for W-ST. With the deviations exceeding the critical value the hypothesis that an ideal random distribution exists must be rejected for both materials. Nevertheless, with the very low deviation of W-TC compared to the value of W-ST its orientation distribution can be seen as being close to random according to Mackenzie. W-ST shows grains elongated in the rolling direction, which are bounded by high angle grain boundaries (HAGBs). Within these grains substructures are confined by low angle grain boundaries (LAGBs). The high number of LAGBs finally explains the much higher deviation from a random distribution than for WTC (Fig. 6).

The grain size distribution was also determined via EBSD analysis. The mean value of the grain size distribution is $4.5 \mu \mathrm{m}$ for $\mathrm{W}-\mathrm{TC}$ and $2.7 \mu \mathrm{m}$ for $\mathrm{W}-\mathrm{ST}$ in the as-produced condition. 

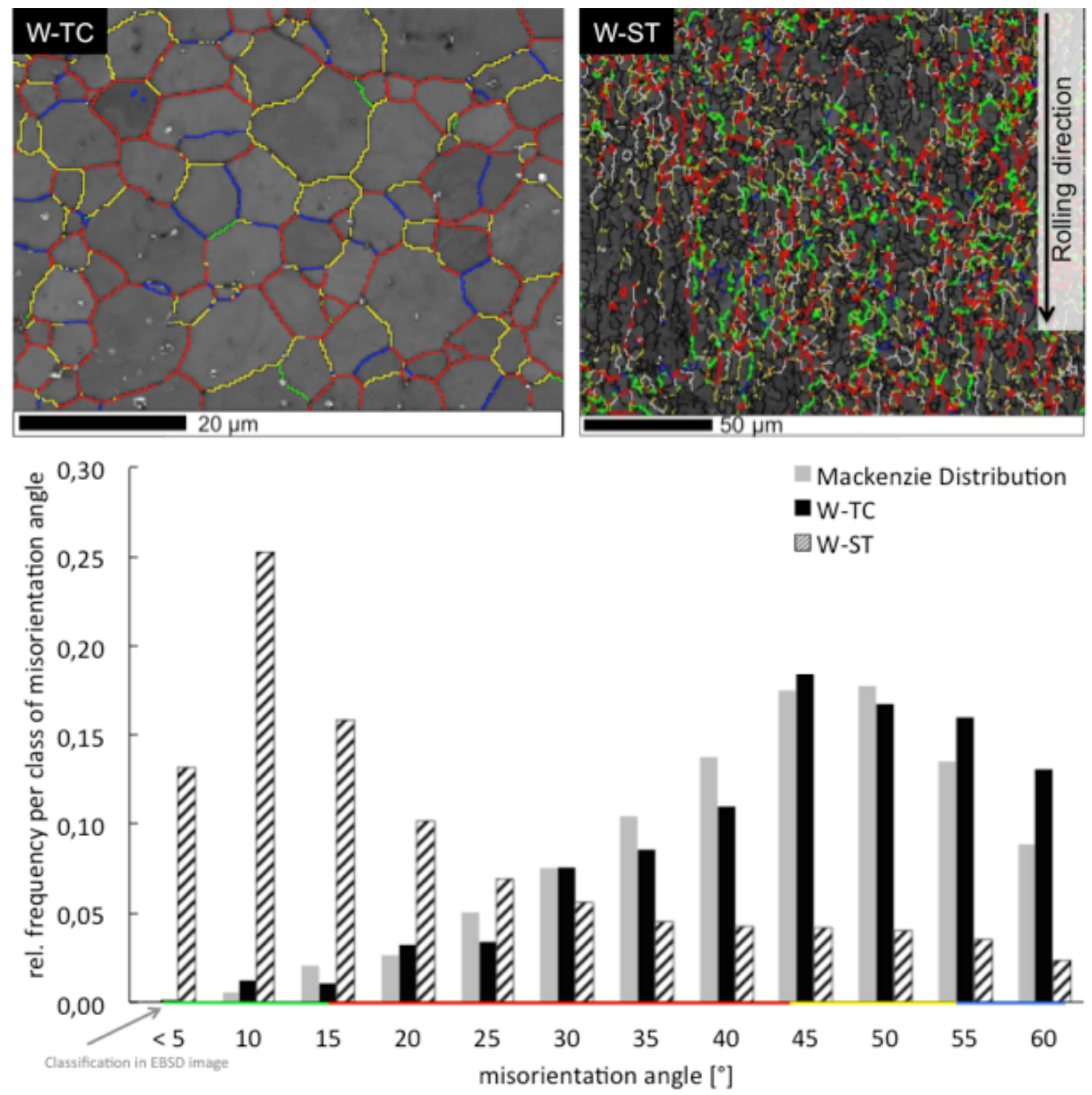

Fig. 6: Distribution of the grain boundary misorientation angle of as-produced W-TC and W-ST in comparison to Mackenzie`s distribution for randomly oriented grains. Grain boundaries with different misorientation angle are classified and marked in the EBSD images at the top.

\subsection{Thermo-cyclic behavior}

Because the peak temperatures in the focal spot could not be measured in the thermal shock test facility it was calculated numerically for W-TC and W-ST by Li et al. [29]. The calculated peak temperature as a function of the absorbed power density is shown in Fig. 7. 


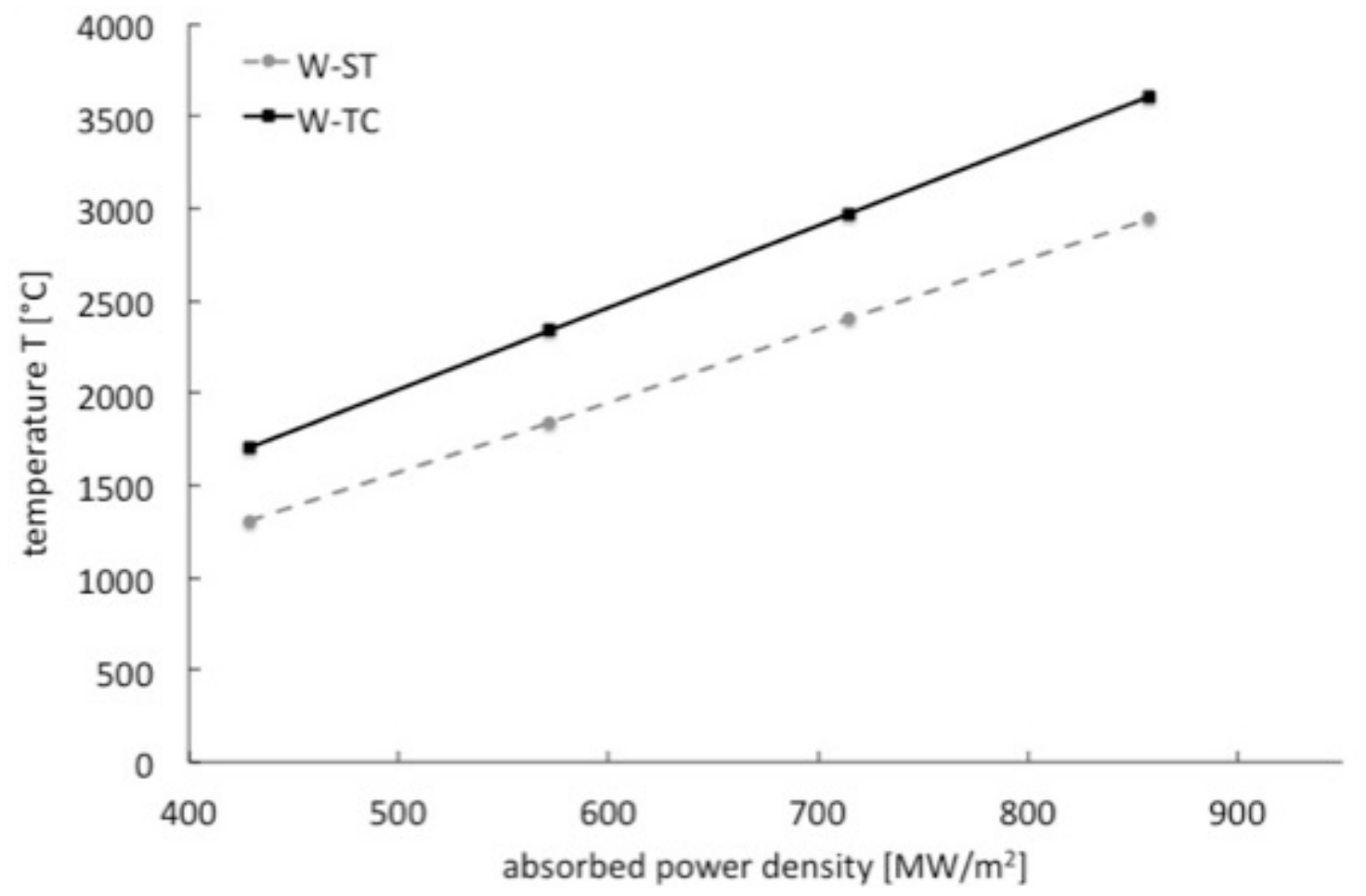

Fig. 7: Calculated peak temperatures of W-TC and W-ST for different absorbed power densities.

Due to the lower thermal diffusivity (Fig. 5) and density of W-TC its peak temperatures are higher than those of W-ST. The peak temperature of W-TC at $572 \mathrm{MW} / \mathrm{m}^{2}$ and $429 \mathrm{MW} / \mathrm{m}^{2}$ are comparable to those of $\mathrm{W}-\mathrm{ST}$ at $715 \mathrm{MW} / \mathrm{m}^{2}$ and $572 \mathrm{MW} / \mathrm{m}^{2}$, respectively. As the thermal stresses, which finally cause the material failure, are related to the peak temperature, the failure development in the samples is evaluated at power densities leading to comparable peak temperatures. For that reason the test matrix of W-ST was shifted to higher power densities (see Tab. 2).

\subsubsection{Thermo-cyclic behavior of $\mathrm{W}$-ST}

SE-images of W-ST (Fig. 8) indicate no modification of the microstructure up to a power density of $572 \mathrm{MW} / \mathrm{m}^{2}$. At $572 \mathrm{MW} / \mathrm{m}^{2}$ recrystallization becomes visible after 25 thermal cycles and a displacement at grain boundaries can be identified after 100 repetitions of loading. Grain boundary failure is clearly evident after 10 repetitions at $715 \mathrm{MW} / \mathrm{m}^{2}$. The higher the applied power density, the less repetitions are required to initiate grain boundary failure. At the highest load of $858 \mathrm{MW} / \mathrm{m}^{2}$ grain boundary cracking is already observed after the first thermal cycle. 


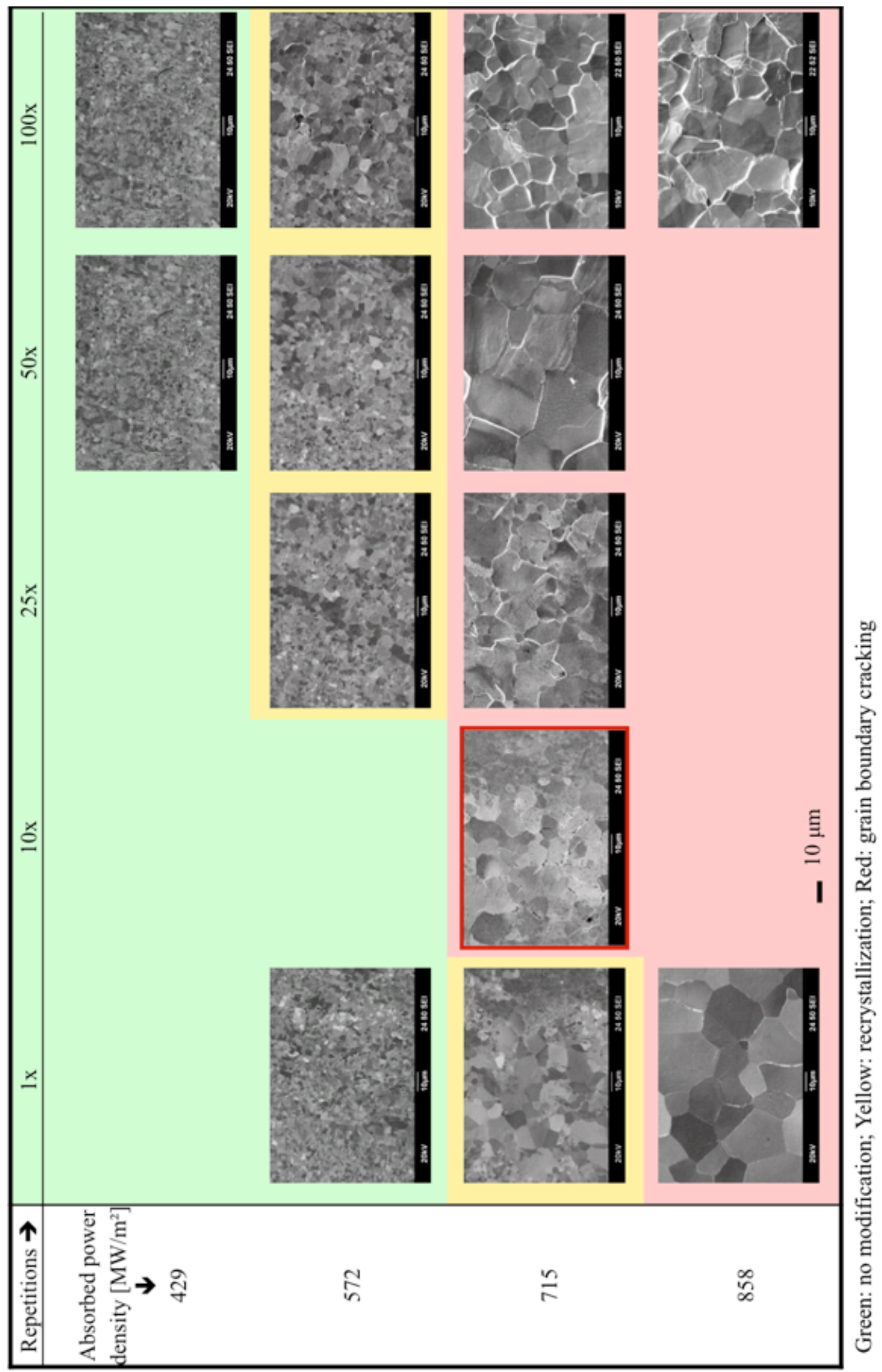

Fig. 8: Recrystallization and cracking threshold of W-ST in dependence of thermal loading (SE-images). The scale bar indicates $10 \mu \mathrm{m}$. An overloading at $715 \mathrm{MW} / \mathrm{m}^{2}$ and 50 repetitions leads to an excessive grain growth. 
The higher magnification in Fig. 9 reveals the development of an intergranular crack pattern in W-ST. Only little deformation and some intragranular defects are visible. These intragranular defects seem to be initiated at former grain boundaries, i.e. before grain growth starts.

1 thermal cycle
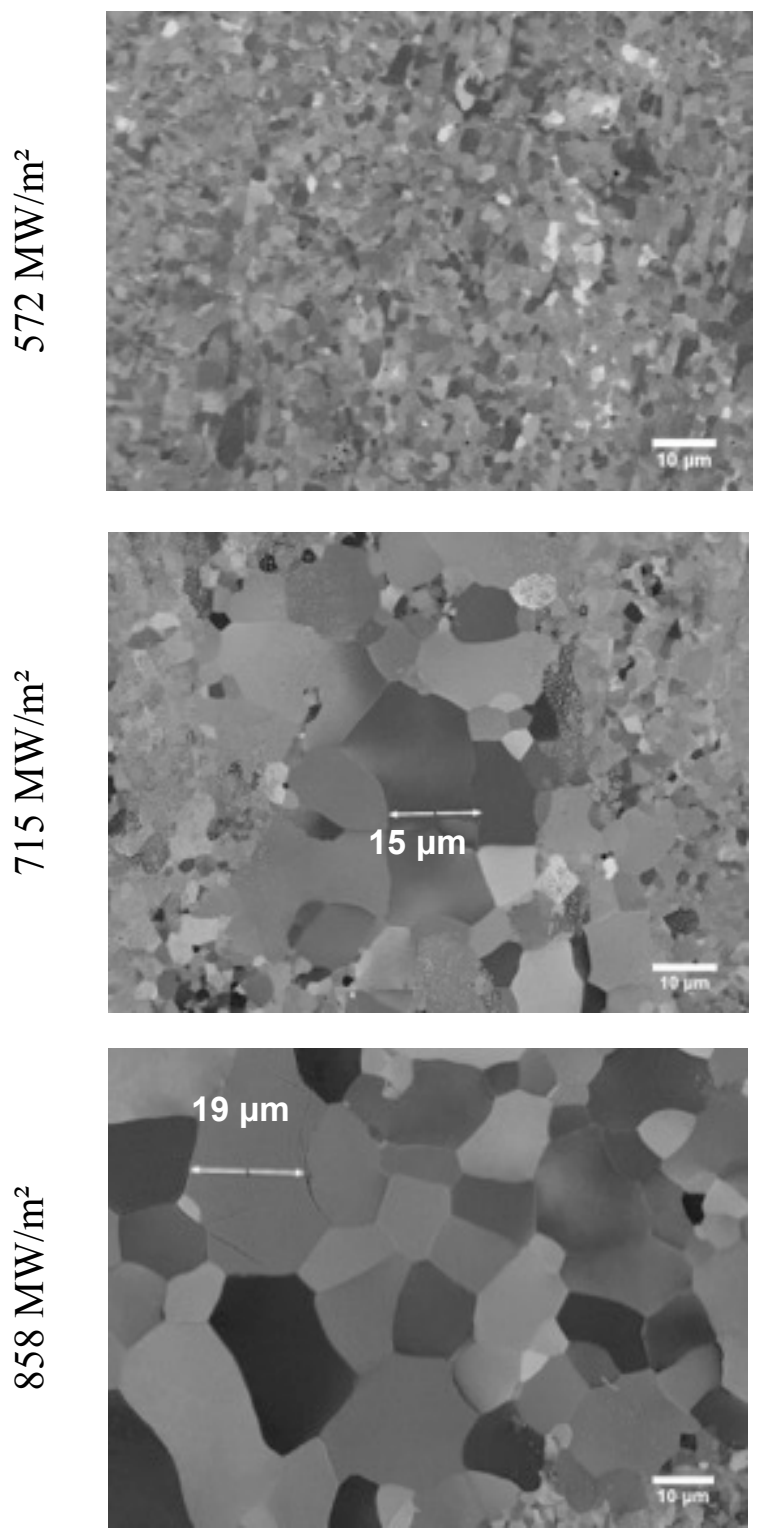

100 thermal cycles
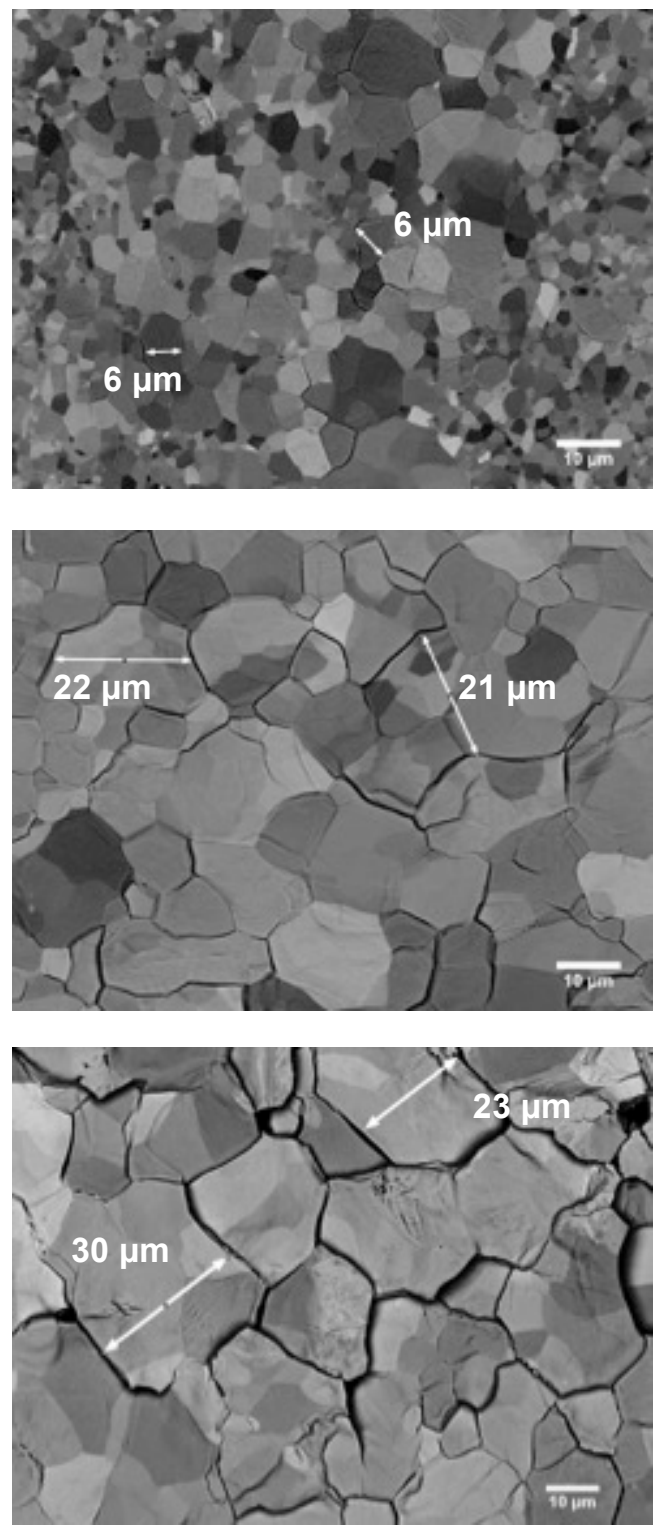

Fig. 9: Recrystallization behavior and development of the crack pattern in W-ST (BSE-images). An increase of grain size and crack distance with increasing power density and number of repetitions is visible (left column: one thermal cycle, right column: 100 thermal cycles).

Hence, a brittle intergranular failure mechanism, with crack distance and crack length increasing with increasing grain size, seems to operate. 


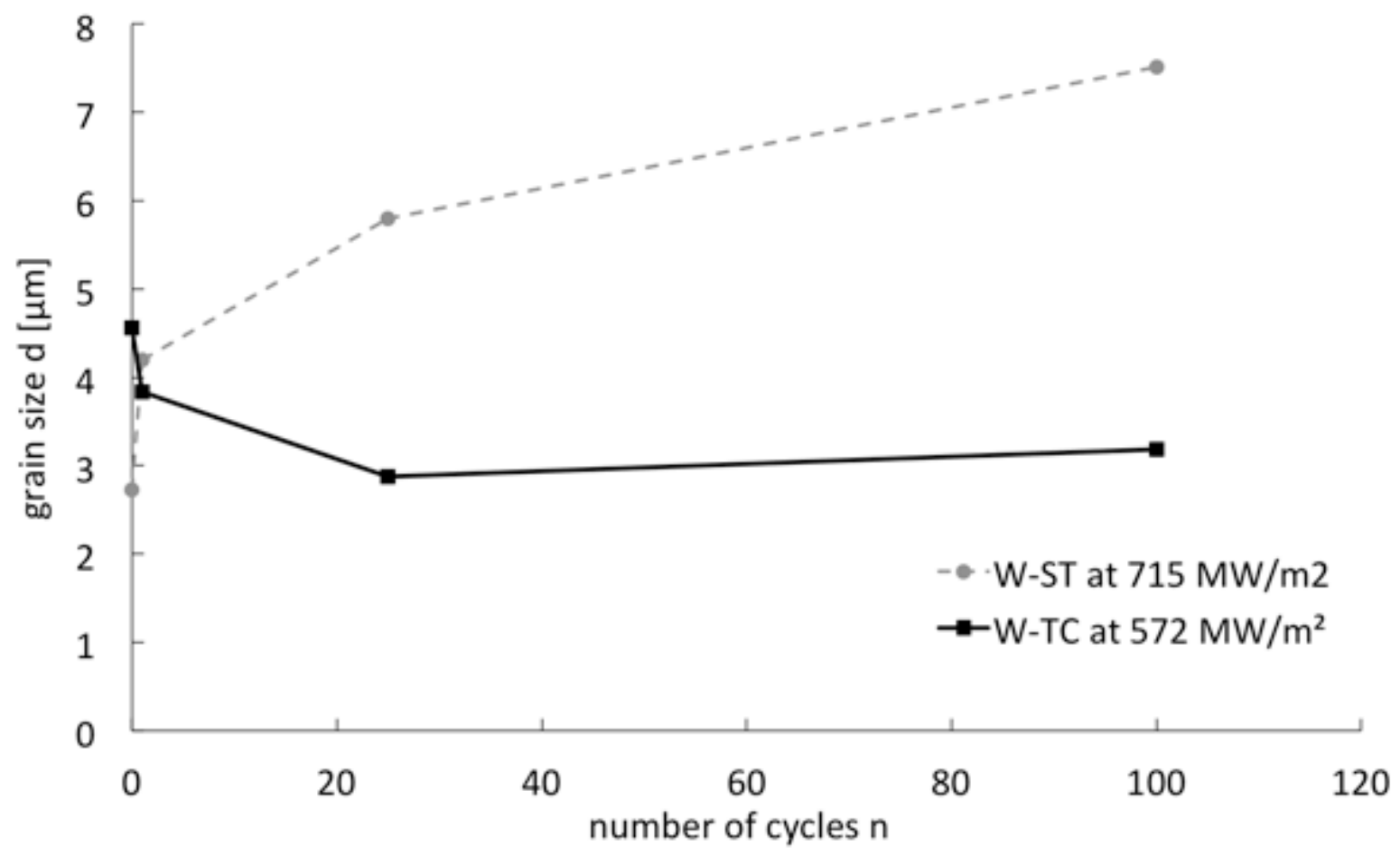

Fig. 10: Development of the mean grain size of W-TC and W-ST with increasing number of thermal cycles. The simulated peak temperature is roughly $2350^{\circ} \mathrm{C}$ for both materials at the shown absorbed power densities.

W-ST exhibits grain growth at power densities above $572 \mathrm{MW} / \mathrm{m}^{2}$ (Fig. 8). The grain size increases with increasing power density and increasing number of load repetitions (Fig. 10). Simultaneously to the significant grain growth the misorientation angle distribution changes. LAGBs are reduced in number and a more even distribution of the angle of misorientation develops (Fig. 11). 



Fig. 11: Development of the distribution of the misorientation angle due to thermal shock loading at W-ST. The fraction of LAGBs is reduced. The light gray section in the upper right image marks the area outside the focal spot that is excluded from EBSD analysis. Grain boundaries with different misorientation angle are classified and marked in the EBSD images on the right.

After 50 repetitions at $715 \mathrm{MW} / \mathrm{m}^{2}$ (Fig. 8) excessive grain growth is observed in WST. The effect does not fit into the trend of the grain size development at this power density and is affiliated to a short overloading during the adjustment of the electron beam current.

\subsubsection{Thermo-cyclic behavior of W-TC}

SE-images of W-TC reveal no failure in the microstructure for power densities below $572 \mathrm{MW} / \mathrm{m}^{2}$ (Fig. 12). First grain boundary failures become visible after 25 repetitions at $572 \mathrm{MW} / \mathrm{m}^{2}$. An intergranular crack pattern is developed with increasing number of repetitions. At $715 \mathrm{MW} / \mathrm{m}^{2}$ grain boundary failures can be identified after the first thermal shock loading. 


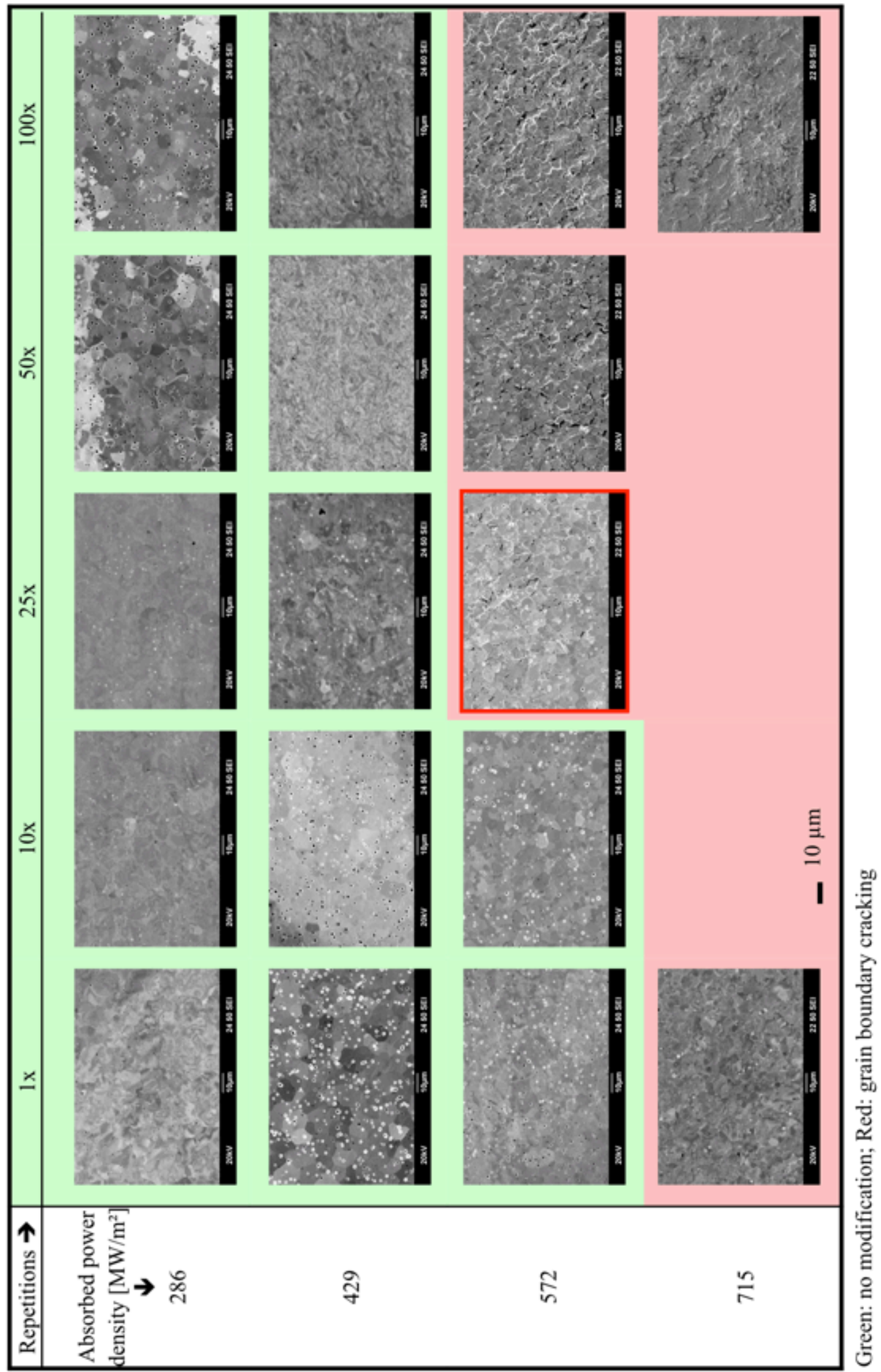

Fig. 12: Recrystallization and cracking threshold of W-TC in dependence of thermal loading (SE-images). The scale bar indicates $10 \mu \mathrm{m}$. 
Simultaneously to crack initiation at $572 \mathrm{MW} / \mathrm{m}^{2}$ a second phase develops at the grain boundaries, especially at triple points (Fig. 13). By XRD-analyses the phase was identified as $\mathrm{W}_{6} \mathrm{C}_{2,54}$. In addition, intragranular structures become visible at power densities above $572 \mathrm{MW} / \mathrm{m}^{2}$. The structures coarsen with increasing power density and increasing number of repetitions and seem to have a unique orientation in each grain and form extrusions at the grain boundary. At the highest loading of $715 \mathrm{MW} / \mathrm{m}^{2}$ and 100 repetitions the deformation of each grain also seems to have a unique orientation and to be related to the orientation of the former intragranular structures.

1 thermal cycle
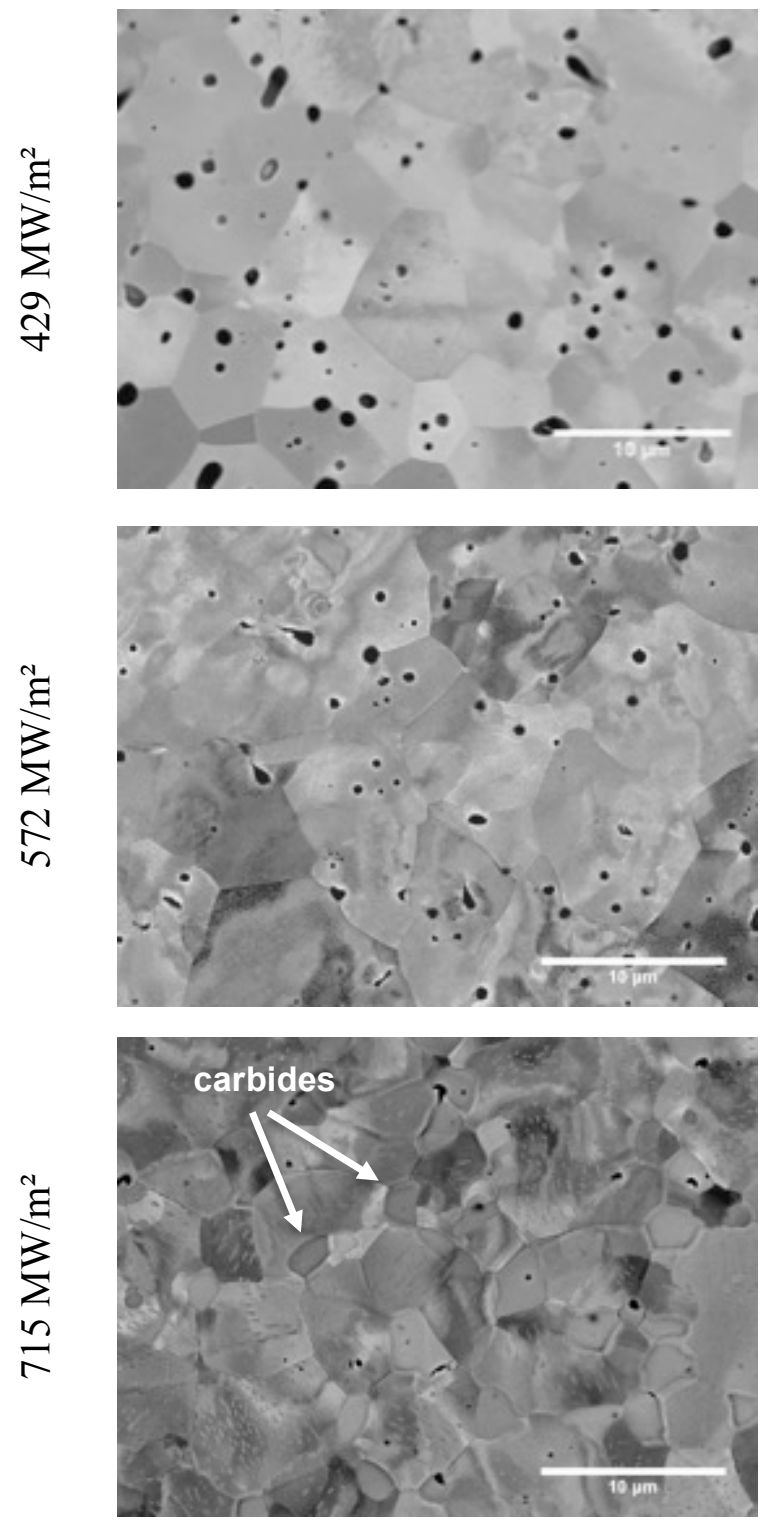

100 thermal cycles
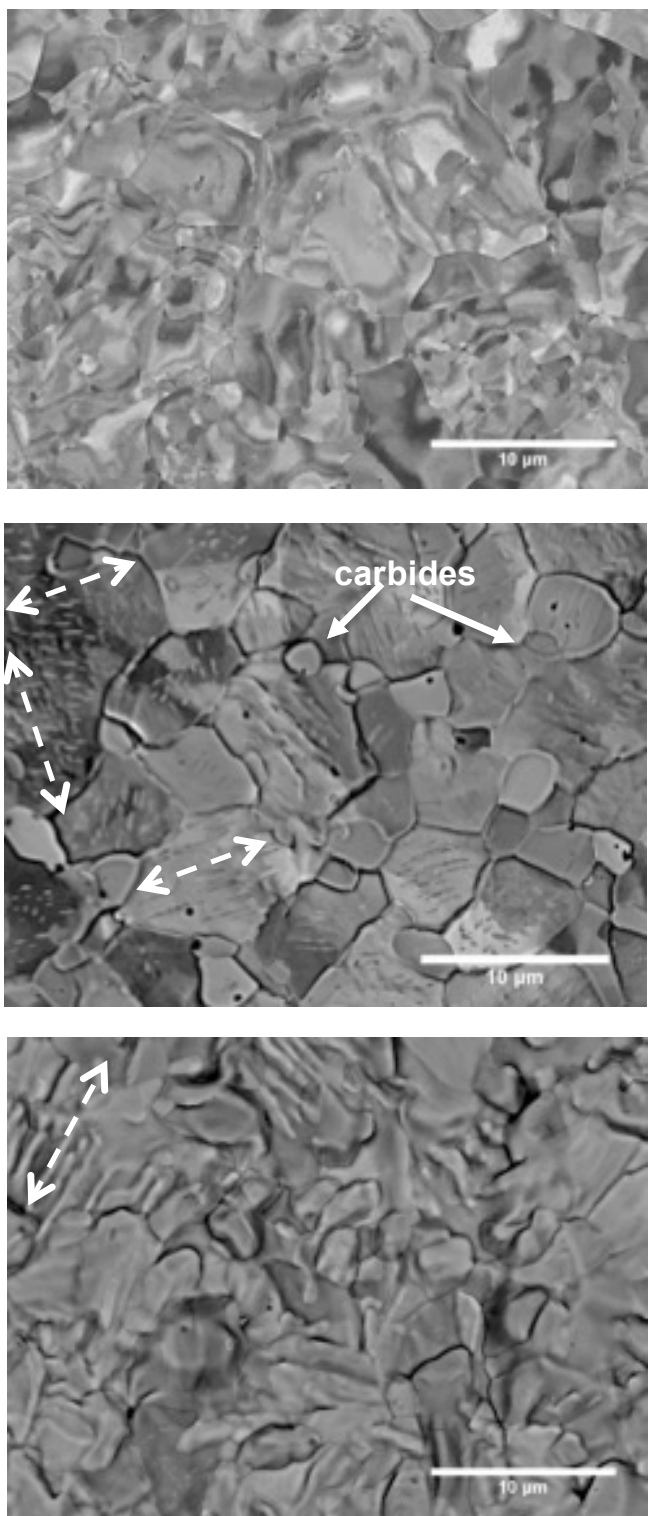

Fig. 13: Recrystallization behavior and development of the crack pattern in W-TC (BSE-images). Arrows indicate the orientation of surface structures and deformation (left column: one thermal cycle, right column: 100 thermal cycles).

At the highest loading $\left(715 \mathrm{MW} / \mathrm{m}^{2}\right)$ the grains are strongly deformed and ductile fracture seems to be occurring. It has to be mentioned that the simulated peak temperature for loading 
with $715 \mathrm{MW} / \mathrm{m}^{2}$ (Fig. 7) is in the range of the melting point of the precipitated carbide phase [40]. Partial melting of this phase could also explain the strongly deformed surface of the samples.

Before cracks are initiated during loading with $572 \mathrm{MW} / \mathrm{m}^{2}$ the BSE images reflect a distorted grain structure at $429 \mathrm{MW} / \mathrm{m}^{2}$ and 100 repetitions (Fig. 13). Additionally the EBSD analysis (Fig. 14) reveals an increase of the number of LAGBs within the existing grain structure at this loading condition. Once cracks are initiated and carbides are precipitated during loading with $572 \mathrm{MW} / \mathrm{m}^{2}$, the number of LAGBs decreases again.


Fig. 14: Development of the distribution of the misorientation angle due to thermal shock loading of W-TC. The fraction of LAGBs increases before cracks are initiated and carbides are precipitated during loading with $572 \mathrm{MW} / \mathrm{m}^{2}$. Grain boundaries with different misorientation angle are classified and marked in the EBSD images.

In contrast to $\mathrm{W}-\mathrm{ST}$ the material $\mathrm{W}-\mathrm{TC}$ seems to exhibit grain refinement during this experiment (Fig. 10). However, it must be taken into account that LAGBs $\left(>5^{\circ}\right)$ are formed, which are interpreted as grain boundaries in the EBSD grain size measurement. Furthermore, carbides are precipitated mainly at theses LAGBs and their triple points which also leads to a reduction of the grain size of the tungsten matrix. 


\subsubsection{Evolution of the surface profile}

The evolution of the surface roughness $R_{a}$ and the maximum waviness $W_{z}$ in the focal spot was investigated at that power density at which the first cracks develop with increasing number of repetitions and at nearly the same peak temperature in the focal spot for both materials (W-ST: $715 \mathrm{MW} / \mathrm{m}^{2}$; W-TC: $572 \mathrm{MW} / \mathrm{m}^{2}$ ). For comparison also the roughness and waviness developing at the highest power density are shown in Fig. 15 and 16. W-ST exhibits a linear increase of $R_{a}$ with increasing number of repetitions. Simultaneously, as shown before, its grain size increases (Fig. 10) and the crack pattern (Fig. 9) evolves. The average roughness $\mathrm{R}_{\mathrm{a}}$ after 50 load cycles, during which a strong grain growth due to overloading is observed (compare Fig. 8), does not fit to this linear trend. The average roughness of W-TC reaches an almost stable value after 50 repetitions (cracking threshold at 10 repetitions) and additional load cycles do not lead to a significant further increase of $\mathrm{R}_{\mathrm{a}}$.

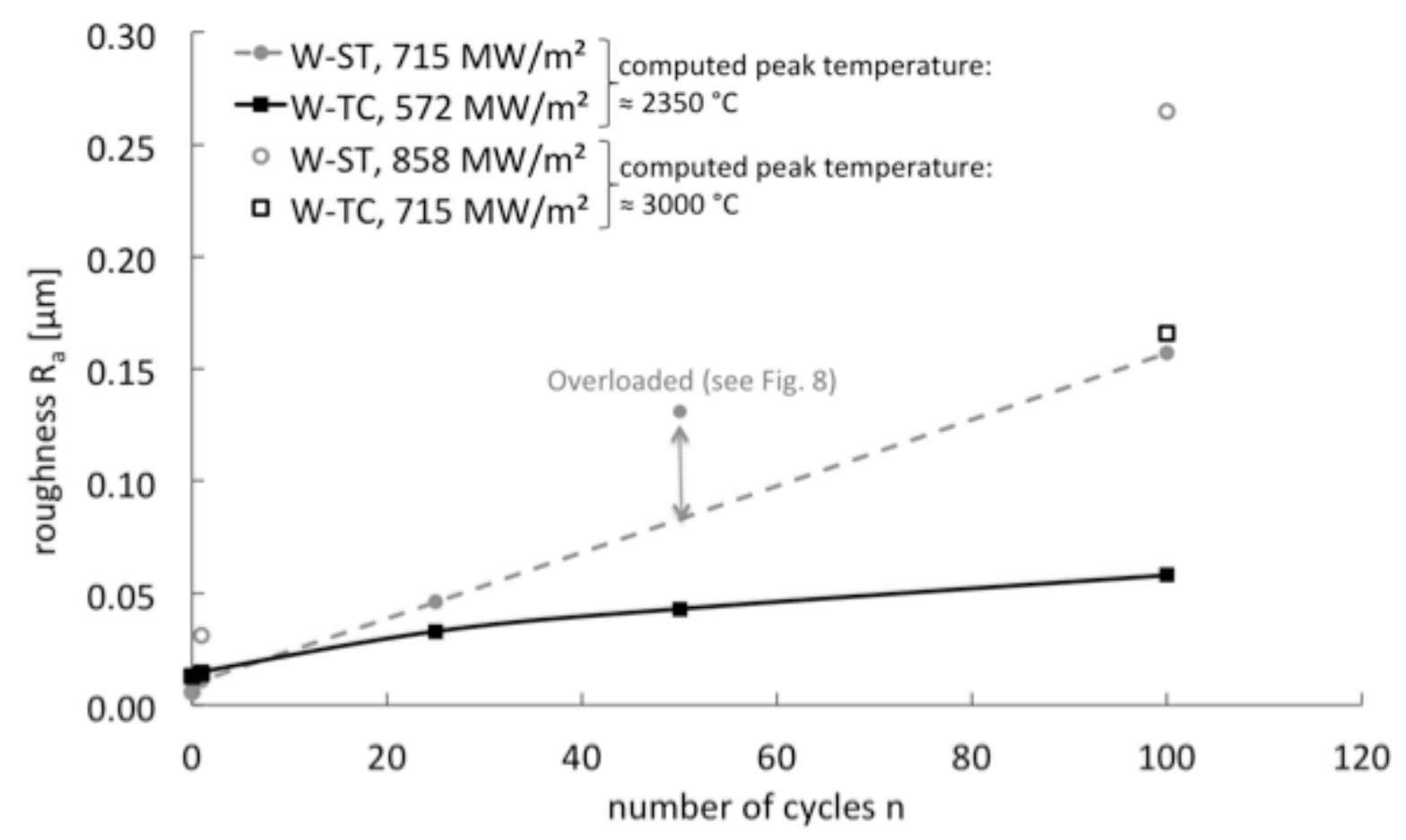

Fig. 15: Evolution of $R_{a}$ with increasing number of load repetitions for the materials W-TC and W-ST.

The evolution of the maximum waviness $\mathrm{W}_{\mathrm{z}}$, which quantifies the elevation of the focal spot, differs from that of $\mathrm{R}_{\mathrm{a}}$. Whereas it reaches a stable level with proceeding crack development (starting at 10 repetitions) for W-ST, it continues to increase for W-TC. This indicates ongoing plastic deformation in W-TC simultaneously to the generation of cracks. 




Fig. 16: Evolution of $\mathrm{W}_{\mathrm{z}}$ with increasing number of load repetitions for the materials $\mathrm{W}-\mathrm{TC}$ and $\mathrm{W}-\mathrm{ST}$.

\section{Discussion}

While tape casting appears to be a suitable route for the production of tungsten components, especially flat ones, with an isotropic and fine-grained microstructure one must carefully monitor porosity and carbon content of the material. Both are to be seen connected to the heat treatment process, during which carbon is dissolved in tungsten, if the binder's polymer chains in the green tape are cracked instead of evaporated. Since lower carbon concentrations can be successfully realized for smaller batch sizes and smaller samples, the gas flow parameters and heating rates in the debinding process have to be adjusted for larger batch sizes. Inspired by the development of PIM for tungsten [28] a higher HIP-pressure is required to eliminate the residual porosity while at the same time keeping the HIPtemperature low enough to prevent undesired grain growth. Since the maximum HIP-pressure was limited to $172 \mathrm{MPa}$ for the available hot isostatic press, our material contains some residual porosity.

Both impurities and pores reduce the thermal diffusivity of W-TC as they act as obstacles to carrier electrons. Porosity also reduces the density of the material. According to equation (1) both a low thermal diffusivity and low density of W-TC reduce the thermal conductivity as compared to W-ST. Therefore, higher surface temperatures are reached in W$\mathrm{TC}$ at a given power density. 
5. 1. Modification of the microstructure during thermal loading

The recrystallization behavior of W-TC and W-ST differs strongly. The thermal shock experiment generates high stresses [29] and strain rates during the first microseconds of the beam pulse (Fig. 17) in the material due to the steep increase of the surface temperature and the related thermal expansion of the material. A strong increase of the dislocation density can be assumed in that period, what is an important premise for the formation of LAGBs [41]. During the remaining time of the thermal shock loading (quasi-steady-state) the strain rate is reduced or even zero at high temperatures, at which diffusion processes become important. Recovery or recrystallization (finally grain growth) is promoted then. At the beginning of the cooling period the strain rate first increases at high temperature and final decreases to zero with further decreasing temperature.



Fig. 17: Computed strain rate and temperature development during one thermal shock pulse (W-ST at $715 \mathrm{MW} / \mathrm{m}^{2}$ ). 
The modification in microstructure at loadings above $0.5 T_{\mathrm{M}}$ and high strain rates are often originating from dynamic recrystallization. The dynamically stable grain size $D_{\mathrm{S}}$ can be calculated from strain rate $\dot{\varepsilon}$ and temperature $T$ using the Zener-Holomon-Parameter $Z$ :

$D_{S}=k \cdot Z^{n} \quad$ with $\quad Z=\dot{\varepsilon} \cdot \exp \left(\frac{Q}{R T}\right)$

where $k$ and $n$ are material constants, $\dot{\varepsilon}$ is the strain rate, $Q$ is the activation energy for plastic flow and $R$ is the gas constant.

Sakai and Jonas [42] described recrystallization under thermo-cyclic conditions. At high strain rates at lower temperatures (high Zener-Hollomon parameter), where the dislocation density increases and substructures (e.g. LAGBs) can form, smaller grain sizes are stable. In contrast a low strain rate at high temperature (diffusion dominates) leads to a coarser grain size as nucleation sites for new grains are reduced in number. During one thermal shock the material experiences both conditions alternately. A schematic dependence of the dynamically stable grain size on the Zener-Holomon-Parameter is given as shown in Fig. 18a.

According to the study of Sakai and Jonas [42] the grain size is inversely proportional to the nucleus density as grain boundaries are the main initial nucleation sites. The initial grain size $D_{0}$ therefore corresponds to $1 / N_{0}\left(N_{0}\right.$ : initial nucleus density) and the dynamic stable grain size $D$ s corresponds to $1 / N_{\mathrm{S}}$ ( $N_{\mathrm{S}}$ : dynamic stable nucleus density). During the thermal shock experiment the initial grain size will according to those theories develop in direction of the dynamically stable grain size $\mathrm{D}_{\mathrm{S}}$. If $D_{0}$ is unequal to $D_{\mathrm{S}}$ before the experiment two options are given for the microstructural development (Fig. 18b):

$$
\begin{aligned}
& D_{01}>D_{\text {S }} \text { (i.e. } N_{\mathrm{S}}<N_{01} \text { ): Grain refining } \\
& D_{02}<D_{\text {S }} \text { (i.e. } N_{02}>N_{\mathrm{S}} \text { ): Grain coarsening }
\end{aligned}
$$

As grain growth is observed after the thermal shock loading for the material W-ST, the initial nucleus density must be higher than the dynamically stable one. The high proportion of LAGBs in W-ST before the experiment constitutes a high number of intergranular nucleation sites, which is reduced during the thermal shock loading by grain growth. The high proportion of LAGBs at the beginning is a result of the thermo-mechanical treatment during the production of rolled tungsten grades.

For W-TC grain refining is observed. However, this is mainly affiliated to the precipitation of a carbide phase within the initial grain structure. This reduces the grain size of the residual tungsten matrix. Due to the lack of any mechanical treatment in the production process no subgrain boundaries (LAGBs) are formed (Fig. 6) and the number of nucleation points is low. A dynamically stable grain size is already achieved in the production process. A similar resistance against grain growth is mentioned for PIM-tungsten in [43]. 

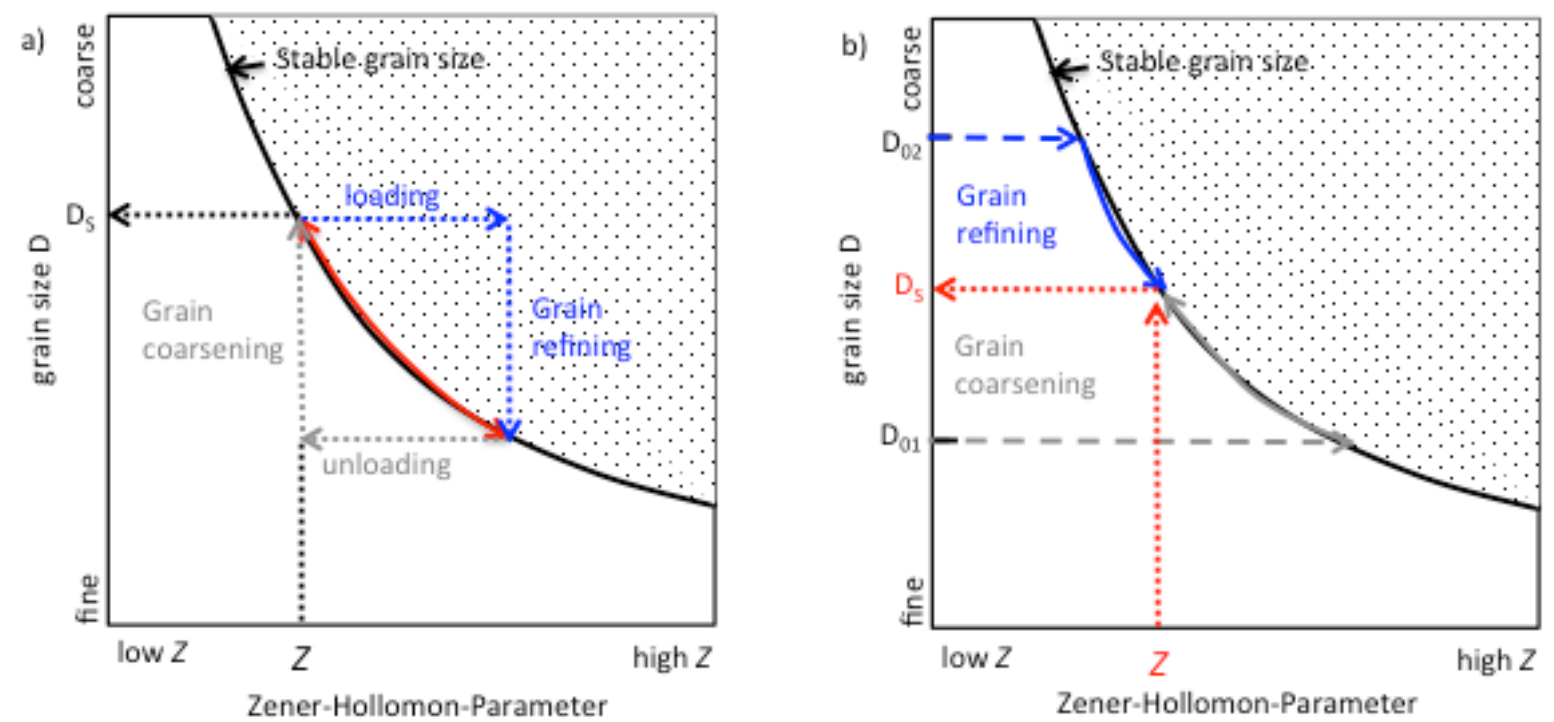

Fig. 18: a) Model of the grain size development during thermo-cyclic loading according to [42]. A high Z-parameter (high strain rate, lower temperature) leads to fine, stable grain sizes; a low Z-parameter (low strain rate, elevated temperature) promotes grain coarsening. b) Evolution of the grain size in dependence of the initial grain size $\mathrm{D}_{0}$ and the Z-parameter.

The thermo-cyclic loading leads to an increase of the proportion of LAGBs within the existing grains (Fig. 14) in W-TC before cracks are initiated. At those loadings the BSEimages (Fig. 13) also reflect an increase of distortions, which is very likely a result of an increased dislocation density and cell formation [41]. As soon as stresses are reduced by crack formation or diffusion is promoted at higher temperatures (due to higher power densities) surface structures are developed within the grain structure. This might on the one hand indicate that recovery processes are then pronounced and reduce the dislocation density by subgrain formation. The surface structures can in this context be understood as small subgrains formed out of dislocation cells. Those subgrains would grow with increasing number of load repetitions and increasing power density. On the other hand, the carbide phase is precipitated at grain boundaries and it is reasonable to assume that also the intragranular surface structures are carbon rich precipitates. Both subgrain formation and precipitation would explain the distinct orientation of the surface structures. Further investigations are needed to explain the substructure formation in detail. Whether or not impurities (higher carbon content) stabilize the grain size of W-TC to some extent cannot be deduced from this experiment.

\subsection{Fracture behavior and surface roughening}

The threshold for cracking of W-ST is at a higher power density than that of W-TC. One should note, however, that this result is markedly affected by the magnitude of the thermal conductivity, which in turn determinates the peak temperature at a given power density. With regard to the peak temperature both materials exhibit the same cracking 
threshold. In our work the development of the crack pattern is compared at the same peak temperature.

The fracture behavior of both investigated tungsten grades is influenced by their grain size. As failures are initiated at the grain boundaries, the grain size and the grain boundary length define the distance of initiated cracks and the crack length, respectively. Both increase for W-ST with increasing power density and number of load repetitions. Simultaneously grain coarsening is observed, which reduces the grain boundary density. The larger crack distance in a coarser grain structure leads to a higher concentration of stresses at fewer grain boundaries. This leads to longer cracks at those boundaries. As a consequence the average roughness increases with increasing grain size.

In contrast, the relatively fine grain structure of W-TC is stable at all loading conditions. Accordingly the distance and length of initiated cracks is stable and shorter than in W-ST in the recrystallized condition. More but shorter cracks are generated. As the distance of cracks (related to the grain size) does not change with increasing number of repetitions the surface roughness $\mathrm{R}_{\mathrm{a}}$ reaches a nearly stable level throughout the development of the crack pattern (Fig. 15). At the same time the average roughness is less than in W-ST as the damage is accumulated in more but smaller cracks.

Gludovatz [11] describes the R-Curve-effect in tungsten in case of intergranular crack propagation. There the bridging of microcracks is an important factor to achieve subcritical crack propagation (pseudo ductility). In fine-grained W-TC the formation of small cracks is pronounced. The final crack pattern in W-TC is also achieved by the bridging of those cracks. A pseudo ductile fracture behavior is therefore more likely in W-TC. This might explain the proceeding increase of the maximum elevation $\left(\mathrm{W}_{\mathrm{Z}}\right)$ in the focal spot although cracks are generated. In contrast, no further increase of the maximum elevation in the focal spot is observed at W-ST, which exhibits larger cracks. On the other hand the deformation at high temperature is in particular driven by diffusion (diffusional flow). The strain rate in diffusional flow is inversely proportional to the grain size [44] and suggests a higher deformation by diffusional flow in W-TC. Diffusional flow is also active when stresses are reduced due to crack formation and it can also explain the proceeding increase of the elevation in the focal spot although cracks are initiated.

\section{Conclusion}

Tape casting was demonstrated to be a new approach for the production of isotropic, fine-grained tungsten. A comparable microstructure to that of PIM-tungsten was achieved. 
Tape cast tungsten (W-TC) and, for comparison, a rolled standard tungsten grade (W-ST) were exposed to thermal shock loadings by an electron beam analogous to the loading of Xray anodes. The main conclusions are:

- The lack of any mechanical treatment in the production process of W-TC leads to a dynamically stable microstructure, which is characterized by an almost random distribution of the grain boundary misorientation angle. W-TC exhibits no grain coarsening. In contrast, strong grain growth is observed in W-ST, which as-delivered exhibits a high proportion of LAGBs that will act as nucleation sites.

- W-TC and W-ST exhibit the same threshold for cracking with regard to the achieved peak temperature in the thermal shock test. Due to the higher thermal diffusivity of WST its cracking threshold is found at a higher power density.

- The development of the surface roughness in the focal spot is strongly influenced by the grain size. Both materials show intergranular crack development. The finer grain size of W-TC leads to shorter cracks and also a shorter distance between these cracks. The damage is therefore accumulated by more but smaller cracks and the roughness in the focal spot increases less than that of W-ST and finally reaches a stable level. The lower increase of the roughness at W-TC is favorable for tungsten anodes in X-ray tubes, as the increase of roughness is a measure for the dose loss [9].

- A higher deformation of the focal spot in W-TC may be caused by an increased contribution of diffusional flow to the total deformation in fine-grained materials. But also the R-Curve behavior, described by Gludovatz [11], seems to be more likely for fine grained materials and explains an ongoing increase of deformation after crack initiation. Further investigations are required to describe the deformation behavior in detail.

- Due to a higher carbon content in W-TC a carbide phase was formed at higher power densities. The experiments did not suggest that this phase negatively influences the fracture behavior. The formation of oriented, intragranular surface structures is in this context interpreted as a phenomenon of dynamic recrystallization (subgrains) or the existence of carbon rich precipitates. Further investigations are needed to analyze these structures in detail.

The next steps in the development of tape cast tungsten will need to focus on the reduction of carbon content and porosity. Both features reduce the thermal conductivity in the first batch of samples. Analogous to the development of PIM-tungsten both tasks seem to be 
feasible by an improvement of the heat treatment parameters (gas flow in the debinding step, HIP-pressure).

The similarities to the production of PIM-tungsten suggest that dispersionstrengthened tungsten (e.g. by $\mathrm{TiC}, \mathrm{Y}_{2} \mathrm{O}_{3}, \mathrm{HfC}$ ) $[14,15]$ might be potential variants within the development of tape cast tungsten.

Acknowledgments: The work was conducted in cooperation between the Siemens AG, the TU Munich and the Max-Planck-Institute for Plasma Physics. Financial support by the Siemens AG, is gratefully acknowledged. 


\section{References}

[1] ITER Physics Basis Co-Chairs, ITER Physics Expert Group Chairs and Unit, ITER Joint Central Team Physics (Eds.), ITER Physics Basis. Nuclear Fusion, 1999. 39(12).

[2] G. Federici, P. Andrew, P. Barabaschi, J. Brooks, R. Doerner, A. Geier, A. Herrmann, G. Janeschitz, K. Krieger, A. Kukushkin, A. Loarte, R. Neu, G. Saibene, M. Shimada, G. Strohmayer, M. Sugihara, Key ITER plasma edge and plasma-material interaction issues, Journal of Nuclear Materials, 313-316 (2003) 11-22.

[3] E.M. Hollmann, G. Arnoux, N. Commaux, N.W. Eidietis, T.E. Evans, R.S. Granetz, A. Huber, D.A. Humphreys, V.A. Izzo, A.N. James, T.C. Jernigan, M. Lehnen, G. Maddaluno, R. Paccagnella, P.B. Parks, V. Philipps, M.L. Reinke, D.L. Rudakov, F. Saint-Laurent, V. Sizyuk, E.J. Strait, J.C. Wesley, C.P.C. Wong, J.H. Yu, Plasma-surface interactions during tokamak disruptions and rapid shutdowns, Journal of Nuclear Materials, 415 (2011) S27-S34.

[4] M. Kikuchi, K. Lackner, M.Q. Tran, Fusion physics, International Atomic Energy Agency, Vienna, 2012.

[5] T.C. Hender, J.C. Wesley, J. Bialek, A. Bondeson, A.H. Boozer, R.J. Buttery, A. Garofalo, T.P. Goodman, R.S. Granetz, Y. Gribov, O. Gruber, M. Gryaznevich, G. Giruzzi, S. Günter, N. Hayashi, P. Helander, C.C. Hegna, D.F. Howell, D.A. Humphreys, G.T.A. Huysmans, A.W. Hyatt, A. Isayama, S.C. Jardin, Y. Kawano, A. Kellman, C. Kessel, H.R. Koslowski, R.J.L. Haye, E. Lazzaro, Y.Q. Liu, V. Lukash, J. Manickam, S. Medvedev, V. Mertens, S.V. Mirnov, Y. Nakamura, G. Navratil, M. Okabayashi, T. Ozeki, R. Paccagnella, G. Pautasso, F. Porcelli, V.D. Pustovitov, V. Riccardo, M. Sato, O. Sauter, M.J. Schaffer, M. Shimada, P. Sonato, E.J. Strait, M. Sugihara, M. Takechi, A.D. Turnbull, E. Westerhof, D.G. Whyte, R. Yoshino, H. Zohm, t.I.M.H.D.D. Group, Magnet, Chapter 3: MHD stability, operational limits and disruptions, Nuclear Fusion, 47 (2007) 128-202.

[6] A. Loarte, G. Saibene, R. Sartori, D. Campbell, V. Riccardo, P. Andrew, G.F. Matthews, J. Paley, W. Fundamenski, T. Eich, A. Herrmann, ELMs and disruptions in ITER: Expected energy fluxes on plasma-facing components from multi-machine experimental extrapolations and consequences for ITER operation, Proceedings of the 21st IAEA Fusion Energy Conference, (2006) 143.

[7] I. Uytdenhouwen, Degradation of first wall materials under ITER relevant loading conditions, in, Universität Gent, 2011, pp. 409.

[8] E. Krestel, Imaging systems for medical diagnostics: Fundamentals and technical solutions : X-Ray diagnostics, computed tomography, nuclear medical diagnostics, magnetic resonance imaging, sonography, biomagnetic diagnostics, Siemens-Aktiengesellchaft, Berlin, 1990.

[9] J. Freudenberger, Auslegung und Schädigung von Röntgenanoden - private communication, Siemens AG, Erlangen, 2012.

[10] B. Gludovatz, S. Wurster, A. Hoffmann, R. Pippan, Fracture toughness of polycrystalline tungsten alloys, International Journal of Refractory Metals and Hard Materials, 28 (2010) 674-678.

[11] B. Gludovatz, S. Wurster, A. Hoffmann, R. Pippan, A study into the crack propagation resistance of pure tungsten, Engineering Fracture Mechanics, 100 (2013) 76-85. 
[12] T. Hirai, G. Pintsuk, J. Linke, M. Batilliot, Cracking failure study of ITER-reference tungsten grade under single pulse thermal shock loads at elevated temperatures, Journal of Nuclear Materials, 390-391 (2009) 751-754.

[13] S.E. Pestchanyi, I. Garkusha, I. Landman, Simulation of tungsten armour cracking due to small ELMs in ITER, Fusion Engineering and Design, 85 (2010) 1697-1701.

[14] G. Pintsuk, D. Blagoeva, J. Opschoor, Thermal shock behavior of tungsten based alloys manufactured via powder injection molding, Journal of Nuclear Materials, 442 (2013) 282286.

[15] G. Pintsuk, H. Kurishita, J. Linke, H. Arakawa, S. Matsuo, T. Sakamoto, S. Kobayashi, K. Nakai, Thermal shock response of fine- and ultra-fine-grained tungsten-based materials, Physica Scripta, T145 (2011) 014060.

[16] G. Pintsuk, A. Prokhodtseva, I. Uytdenhouwen, Thermal shock characterization of tungsten deformed in two orthogonal directions, Journal of Nuclear Materials, 417 (2011) $481-486$.

[17] G. Pintsuk, I. Uytdenhouwen, Thermo-mechanical and thermal shock characterization of potassium doped tungsten, International Journal of Refractory Metals and Hard Materials, 28 (2010) 661-668.

[18] G. Ritz, Performance of Tungsten-Based Materials and Components under ITER and DEMO Relevant Steady-State Thermal Loads, in: Fakultät für Maschinenwesen, RheinischWestfälischen Technischen Hochschule Aachen, 2010, pp. 128.

[19] D. Rupp, R. Mönig, P. Gruber, S.M. Weygand, Fracture toughness and microstructural characterization of polycrystalline rolled tungsten, International Journal of Refractory Metals and Hard Materials, 28 (2010) 669-673.

[20] I. Uytdenhouwen, M. Decréton, T. Hirai, J. Linke, G. Pintsuk, G. van Oost, Influence of recrystallization on thermal shock resistance of various tungsten grades, Journal of Nuclear Materials, 363-365 (2007) 1099-1103.

[21] M. Wirtz, Thermal Shock Behaviour of Different Tungsten Grades under Varying Conditions, Forschungszentrum Jülich GmbH, 2013, pp. 130.

[22] S. Wurster, B. Gludovatz, A. Hoffmann, R. Pippan, Fracture behaviour of tungstenvanadium and tungsten-tantalum alloys and composites, Journal of Nuclear Materials, 413 (2011) 166-176.

[23] Z. Zhou, G. Pintsuk, J. Linke, T. Hirai, M. Rödig, Y. Ma, C. Ge, Transient high heat load tests on pure ultra-fine grained tungsten fabricated by resistance sintering under ultra-high pressure, Fusion Engineering and Design, 85 (2010) 115-121.

[24] B. Gludovatz, Wurster, S., T. Weingärtner, A. Hoffmann, R. Pippan, Influence of impurities on the fracture behaviour of tungsten, Philosophical Magazine, 91 (2011) 30063020 .

[25] H. Kurishita, S. Matsuo, H. Arakawa, T. Sakamoto, S. Kobayashi, K. Nakai, T. Takida, M. Kato, M. Kawai, N. Yoshida, Development of re-crystallized W-1.1\%TiC with enhanced 
room-temperature ductility and radiation performance, Journal of Nuclear Materials, 398 (2010) 87-92.

[26] J. Opschoor, KeyTec and ECN collaborate on components for extreme heat based on metal injection moulding, 2012. [14.10.2013]; Available from:

https://http://www.ecn.nl/news/item/keytec-and-ecn-collaborate-on-components-for-extremeheat-based-on-metal-injection-moulding/.

[27] B. Zeep, P. Norajitra, V. Piotter, J. Boehm, R. Ruprecht, J. Hausselt, Net shaping of tungsten components by micro powder injection moulding, Fusion Engineering and Design, 82 (2007) 2660-2665.

[28] B. Zeep, Prozessentwicklung für das Mikro-Pulverspritzgießen von Wolfram, in: F.K.i.d. Helmholtz-Gemeinschaft (Ed.) Wissenschaftliche Bericht, IFM 3, Universität Freiburg, 2007.

[29] M. Li, M. Sommerer, E. Werner, S. Lampenscherf, T. Steinkopff, P. Wolfrum, J.-H. You, Experimental and computational study of damage behavior of tungsten under high energy electron beam irradiation, Engineering Fracture Mechanics, 135 (2015) 64-80.

[30] Y. Lian, X. Liu, Z. Cheng, J. Wang, J. Song, Y. Yu, J. Chen, Thermal shock performance of CVD tungsten coating at elevated temperatures, Journal of Nuclear Materials, 455 (2014) 371-375.

[31] A. Day, P. Trimby, Channal 5: User Manual, Hobro, Denmark, 2004.

[32 J.K. Mackenzie, Second paper on statistics associated with the random disorientation of cubes, Biometrika, 45 (1958 ) 229-240.

[33] J.K. Mackenzie, The distribution of rotation axes in a random aggregate of cubic crystals, Acta Metallurgica, 12 (1964) 223-225..

[34] A. Manhard, G. Matern, M. Balden, A Step-By-Step Analysis of the Polishing Process for Tungsten Specimens, Practical Metallography, 50 (2013) 5-16.

[35] KEYENCE Corporation, 3D-Laserscanningmikroskop VK-X100K/X200K:

Referenzhandbuch, Osaka, 2012.

[36] NETZSCH-Gerätebau GmbH, Laser Flash Analysis - LFA: Method, Technique, Applications, 2013. [14.10.2013]; Available from: http://www.netzsch.com/n87885

[37] Siemens AG, Siemens internal report of physical parameters of tungsten, 1995.

[38] W. Prantl, E. Werner, H.P. Stüwe, Statistical treatment of measured orientation relationships, Textures \& Microstructures, 8 \& 9 (1988) 483-492.

[39] J. Hartung, B. Elpelt, K.H. Klösener, Statistik, Lehr- und Handbuch der angewandten Statistik, Oldenbourg, 2009.

[40] S.V. Nagender Naidu, P. Rama Rao, Phase Diagrams of Binary Tungsten Alloys, in, ASM International, 1991, pp. 326.

[41] G.T. Gray, High-Strain-Rate Deformation: Mechanical Behavior and Deformation Substructures Induced, Annu. Rev. Mater. Res., 42 (2012) 285-303. 
[42] T. Sakai, J.J. Jonas, Overview no. 35 Dynamic recrystallization: Mechanical and microstructural considerations, Acta Metallurgica, 32 (1984) 189-209.

[43] D.T. Blagoeva, J. Opschoor, J.G. van der Laan, C. Sârbu, G. Pintsuk, M. Jong, T. Bakker, P. Pierick, H. Nolles, Development of tungsten and tungsten alloys for DEMO divertor applications via MIM technology, Journal of Nuclear Materials, 442 (2013) 198-203.

[44] H.J. Frost, M.F. Ashby, Deformation-Mechanism Maps: The Plasticity and Creep of Metals and Ceramics, Pergamon, Oxford, 1982. 